ARTICLE

\title{
Bismuth atom tailoring of indium oxide surface frustrated Lewis pairs boosts heterogeneous $\mathrm{CO}_{2}$ photocatalytic hydrogenation
}

Tingjiang Yan ${ }^{1,2 凶}, \mathrm{Na} \mathrm{Li}^{3 凶}$, Linlin Wang ${ }^{1}$, Weiguang Ran ${ }^{1}$, Paul N. Duchesne ${ }^{2}$, Lili Wan², Nhat Truong Nguyen (1) ${ }^{2}$, Lu Wang ${ }^{2}$, Meikun $\mathrm{Xia}^{2}$ \& Geoffrey A. Ozin (1) ${ }^{2 凶}$

The surface frustrated Lewis pairs (SFLPs) on defect-laden metal oxides provide catalytic sites to activate $\mathrm{H}_{2}$ and $\mathrm{CO}_{2}$ molecules and enable efficient gas-phase $\mathrm{CO}_{2}$ photocatalysis. Lattice engineering of metal oxides provides a useful strategy to tailor the reactivity of SFLPs. Herein, a one-step solvothermal synthesis is developed that enables isomorphic replacement of Lewis acidic site $\ln ^{3+}$ ions in $\ln _{2} \mathrm{O}_{3}$ by single-site $\mathrm{Bi}^{3+}$ ions, thereby enhancing the propensity to activate $\mathrm{CO}_{2}$ molecules. The so-formed $\mathrm{Bi}_{x} \ln _{2-x} \mathrm{O}_{3}$ materials prove to be three orders of magnitude more photoactive for the reverse water gas shift reaction than $\ln _{2} \mathrm{O}_{3}$ itself, while also exhibiting notable photoactivity towards methanol production. The increased solar absorption efficiency and efficient charge-separation and transfer of $\mathrm{Bi}_{x} \ln _{2-x} \mathrm{O}_{3}$ also contribute to the improved photocatalytic performance. These traits exemplify the opportunities that exist for atom-scale engineering in heterogeneous $\mathrm{CO}_{2}$ photocatalysis, another step towards the vision of the solar $\mathrm{CO}_{2}$ refinery.

\footnotetext{
${ }^{1}$ The Key Laboratory of Life-Organic Analysis, College of Chemistry and Chemical Engineering, Qufu Normal University, 273165 Qufu, Shandong, People's Republic of China. ${ }^{2}$ Materials Chemistry and Nanochemistry Research Group, Solar Fuels Cluster, Department of Chemistry, University of Toronto, 80 St. George Street, Toronto, ON M5S 3H6, Canada. ${ }^{3}$ Qufu Normal University Library, Qufu Normal University, 273165 Qufu, Shandong, People's Republic of China.

凶email: tingjiangn@163.com; chessmantj@163.com; gozin@chem.utoronto.ca
} 
$\mathrm{T}$ he increasing energy demands of civil society have accelerated the consumption of coal, oil and natural gas, and associated greenhouse gas emissions. This situation is tipping the delicate balance of $\mathrm{CO}_{2}$ in our atmosphere, leading to global warming. To this end, the photocatalytic hydrogenation of $\mathrm{CO}_{2}$ into value-added chemicals and fuels has attracted global attention, touted a promising means of achieving a carbonneutral economy ${ }^{1-3}$. Although materials such as $\mathrm{Pd} / \mathrm{Nb}_{2} \mathrm{O}_{5}{ }^{4}, \mathrm{Ru} /$ $\mathrm{Al}_{2} \mathrm{O}_{3}{ }^{5}, \mathrm{LDH}$ nanosheets, ${ }^{6}$, and $\mathrm{Co}-\mathrm{PS} @ \mathrm{SiO}_{2}{ }^{7}$ have been successfully employed as photocatalysts for $\mathrm{CO}_{2}$ hydrogenation, a photocatalyst does not currently exist that can meet all the stringent requirements for practical application, including a broad solar response, high conversion efficiency, robust stability and low cost. This renders the design of a practical photocatalyst for $\mathrm{CO}_{2}$ hydrogenation a challenge.

Besides catalyst modifications designed to broaden spectral response and improve charge transfer efficiency, it is also important to accelerate conversion rates of $\mathrm{H}_{2}$ or $\mathrm{CO}_{2}$ on specially designed surface sites to boost photon and energy efficiency. Recently, surface frustrated Lewis pairs (SFLPs) have shown a propensity towards $\mathrm{H}_{2}$ dissociation and $\mathrm{CO}_{2}$ activation, a key enabler for many catalytic reactions, including hydrogenation, hydroamination and $\mathrm{CO}_{2}$ reduction ${ }^{8-10}$. Generally speaking, SFLPs comprise proximal Lewis acidic and Lewis basic sites providing synergetic activation of reactant molecules. For example, SFLPs sites in the $\operatorname{In}_{2} \mathrm{O}_{3-x}(\mathrm{OH})_{y}$ photocatalyst, comprises a coordinately unsaturated Lewis acidic In atom, proximal to an oxygen vacancy and an adjacent Lewis basic hydroxide group, enable the heterolysis of $\mathrm{H}_{2}$ and reaction with $\mathrm{CO}_{2}$ to form either $\mathrm{CO}$ or $\mathrm{CH}_{3} \mathrm{OH}^{11-13}$. As well, SFLPs involving coordinately unsaturated surface cobalt sites adjacent to surface hydroxides in the $\mathrm{CoGeO}_{2}(\mathrm{OH})_{2}$ photocatalyst form $\mathrm{CH}_{4}$ from $\mathrm{H}_{2} \mathrm{O}$ and $\mathrm{CO}_{2}{ }^{14}$. In addition, SFLPs in oxygen vacancy laden $\mathrm{CeO}_{2}$ bearing SFLPs catalyze the hydrogenation of alkenes and alkynes ${ }^{15}$. All of these cases utilize oxygen vacancies and hydroxides to engineer the catalytic activity of SFLPs. How to tailor the reactivity of the SFLPs themselves is rarely mentioned.

Indium sesquioxide $\left(\operatorname{In}_{2} \mathrm{O}_{3}\right)$ is proving to be a promising catalyst for the thermal hydrogenation of $\mathrm{CO}_{2}$ to $\mathrm{CH}_{3} \mathrm{OH}$ or $\mathrm{CO}^{16-18}$. Experimental and computational studies of $\mathrm{CO}_{2}$ hydrogenation over oxygen vacancy laden $\mathrm{In}_{2} \mathrm{O}_{3}$ revealed that methanol formation was favored over the reverse water gas shift (RWGS) reaction ${ }^{19,20}$. Methanol production was remarkably enhanced when $\mathrm{In}_{2} \mathrm{O}_{3}$ was supported on $\mathrm{ZrO}_{2}$ arising from electronic support effects ${ }^{21}$. A bifunctional catalyst composed of partially reduced $\mathrm{In}_{2} \mathrm{O}_{3}$ supported on HZSM-5 could convert $\mathrm{CO}_{2}$ directly into gasoline-range hydrocarbons with a $78.6 \%$ selectivity due to the synergistic effects of these two components ${ }^{22}$. By controlling the degree of non-stoichiometry in $\mathrm{In}_{2} \mathrm{O}_{3-x}$, a black indium oxide catalyst, which utilized the entire solar spectrum, facilitated the photothermal RWGS reaction under ambient conditions with $100 \%$ selectivity $^{23}$. Tailoring the electronic properties of $\operatorname{In}_{2} \mathrm{O}_{3}$ can also be achieved via replacement of an indium atom in the lattice with a $\mathrm{H}_{2}$ spillover palladium atom, although the rarity and cost of palladium could prove an issue for its practical implementation ${ }^{24}$.

Bismuth, regarded as a "green" element, has a long and fascinating history ${ }^{25}$. The Incas in sixteenth century South America, made corrosion resistant bronzes for their knives by mixing bismuth with $\operatorname{tin}^{26}$. Paracelsus in fifteenth century Germany, recognized bismuth as a non-toxic brother to lead ${ }^{27}$. Since, it is finding myriad eco-friendly uses from cosmetics and personal care products to medicine and lubricants. Most recently it has proved to be a serious contender for replacing toxic lead halide perovskite materials in solar cells with non-toxic bismuth oxyiodide, retaining a comparable energy conversion efficiency of
$22 \%{ }^{28}$. Contextually, bismuth materials with layered structures and visible light absorption properties, exemplified by $\mathrm{BiOX}$ $(\mathrm{X}=\mathrm{Cl}, \mathrm{Br}, \mathrm{I}), \mathrm{Bi}_{2} \mathrm{MO}_{6}(\mathrm{M}=\mathrm{Mo}, \mathrm{W}), \mathrm{BiVO}_{4}$ and $\mathrm{Bi}_{2} \mathrm{~S}_{3}$, behave as photocatalysts to be applied in dye degradation, water and carbon dioxide reduction ${ }^{29}$.

Described herein, we developed a facile solvothermal route to achieve atom-precise substitution of $\mathrm{Bi}^{3+}$ for $\operatorname{In}^{3+}$ sites in $\operatorname{In}_{2} \mathrm{O}_{3}$ and realize the tailor of the reactivity of SFLPs, as well as the electronic properties of $\operatorname{In}_{2} \mathrm{O}_{3}$. To amplify, by substituting cheaper and safer bismuth for indium in UV absorbing $\operatorname{In}_{2} \mathrm{O}_{3}$, one can create the broad-spectrum UV-Vis light absorber $\mathrm{Bi}_{x} \mathrm{In}_{2-x} \mathrm{O}_{3}$. Significantly, single-site $\mathrm{Bi}^{3+}$ substitution for $\mathrm{In}^{3+}$ provides strong Lewis acidic/basic $\mathrm{Bi}^{3+}-\mathrm{O}^{2-}$ pairs that enhance $\mathrm{CO}_{2}$ adsorption and activation, while $\mathrm{Bi} 6 \mathrm{~s}^{2}$ lone-pair electrons create mid-gap energy states. Atom-precise lattice engineering of this kind, boosts the reactivity of SFLPs and the harvesting efficiency of solar photons by $\mathrm{Bi}_{x} \mathrm{In}_{2-x} \mathrm{O}_{3}$ compared to $\mathrm{In}_{2} \mathrm{O}_{3}$, which enables 1000 times photoactivity enhancement of the RWGS reaction together with a noticeable increase in the production of solar methanol.

\section{Results}

Structural characterizations of single-site $\mathrm{Bi}_{x} \mathrm{In}_{2-x} \mathrm{O}_{3} . \mathrm{Bi}_{x} \mathrm{In}_{2-}$ ${ }_{x} \mathrm{O}_{3}$ nanocrystals were prepared via a one-step solvothermal route, in which the molar ratio of $\mathrm{Bi}$ could be controlled by adjusting the concentration of $\mathrm{Bi}\left(\mathrm{NO}_{3}\right)_{3}$ and $\operatorname{In}\left(\mathrm{NO}_{3}\right)_{3}$ precursors. The mole percent $\mathrm{Bi}$ content of each sample in the $\mathrm{Bi}_{x} \mathrm{In}_{2-x} \mathrm{O}_{3}$ series of nanocrystals was determined using inductively coupled plasma mass spectrometry (ICP-MS, Supplementary Table 1). Transmission electron microscopy (TEM) shows that the pristine $\operatorname{In}_{2} \mathrm{O}_{3}$ nanocrystals are flower-like agglomerates of small nanocrystals with an average size of $3.7 \mathrm{~nm}$ (Supplementary Fig. 1). $\mathrm{Bi}^{3+}$ substitution results in similarly sized $\mathrm{Bi}_{x} \mathrm{In}_{2-}$ ${ }_{x} \mathrm{O}_{3}$ nanocrystals $(3.5 \mathrm{~nm})$ that show lattice fringes with a spacing of $2.92 \AA$, corresponding to the (222) plane of bcc $\mathrm{In}_{2} \mathrm{O}_{3}$ (Supplementary Fig. 2). The obtained selected area electron diffraction pattern shown no evidence of any metallic $\mathrm{Bi}$ or $\mathrm{Bi}_{2} \mathrm{O}_{3}$. Most significantly, spherical aberration-corrected scanning transmission electron microscopy (STEM) images provide an insightful and distinct result, in which atomically dispersed single-site Bi atoms are revealed under these high-resolution imaging conditions as bright dots (Fig. 1a, b). Energy-dispersive X-ray spectroscopy (EDS) line scans and elemental mapping (Fig. 1c and Supplementary Fig. 3) provided further evidence for the homogeneous distribution of elemental $\mathrm{Bi}$ in these $\mathrm{Bi}_{x} \mathrm{In}_{2-x} \mathrm{O}_{3}$ nanocrystals.

The phase structure of the obtained $\mathrm{Bi}_{x} \mathrm{In}_{2-x} \mathrm{O}_{3}$ nanocrystals was studied by powder X-ray diffraction (PXRD, Fig. 1d). All the $\mathrm{Bi}_{x} \mathrm{In}_{2-x} \mathrm{O}_{3}$ nanocrystals displayed nearly identical XRD patterns diagnostic of face-centered cubic $\operatorname{In}_{2} \mathrm{O}_{3}$ except that the diffraction peaks were shifted to lower $2 \theta$ values relative to those of pristine $\mathrm{In}_{2} \mathrm{O}_{3}$. This result indicates $\mathrm{In}^{3+}$ were isomorphously substituted by $\mathrm{Bi}^{3+}$, which has a larger ionic radius than $\operatorname{In}^{3+}$ (i.e., $0.96 \AA$ versus $0.81 \AA$ ). This conclusion is supported by the In $3 \mathrm{~d}$ peaks in the corresponding X-ray photoelectron spectroscopy (XPS) spectra (Supplementary Fig. 4a), which exhibited a gradual positive energy shift for $\mathrm{Bi}_{x} \mathrm{In}_{2-x} \mathrm{O}_{3}$ nanocrystals relative to pure $\mathrm{In}_{2} \mathrm{O}_{3}$, that is attributed to the higher electronegativity of $\mathrm{Bi}^{3+}$ compared to $\mathrm{In}^{3+}$. The spin-orbit coupled doublet of Bi $4 \mathrm{f}$ XPS peaks at $158.6 \mathrm{eV}$ and $163.9 \mathrm{eV}$ define the oxidation state of bismuth as $\mathrm{Bi}^{3+}$ rather than $\mathrm{Bi}^{0}$ (Supplementary Fig. 4b), following the isomorphous substitution of $\mathrm{In}^{3+}$ by $\mathrm{Bi}^{3+}$. The electron paramagnetic resonance (EPR) spectra of $\mathrm{Bi}_{x} \mathrm{In}_{2-x} \mathrm{O}_{3}$ nanocrystals at both room temperature and $77 \mathrm{~K}$ revealed the absence of paramagnetic species, thereby providing further 

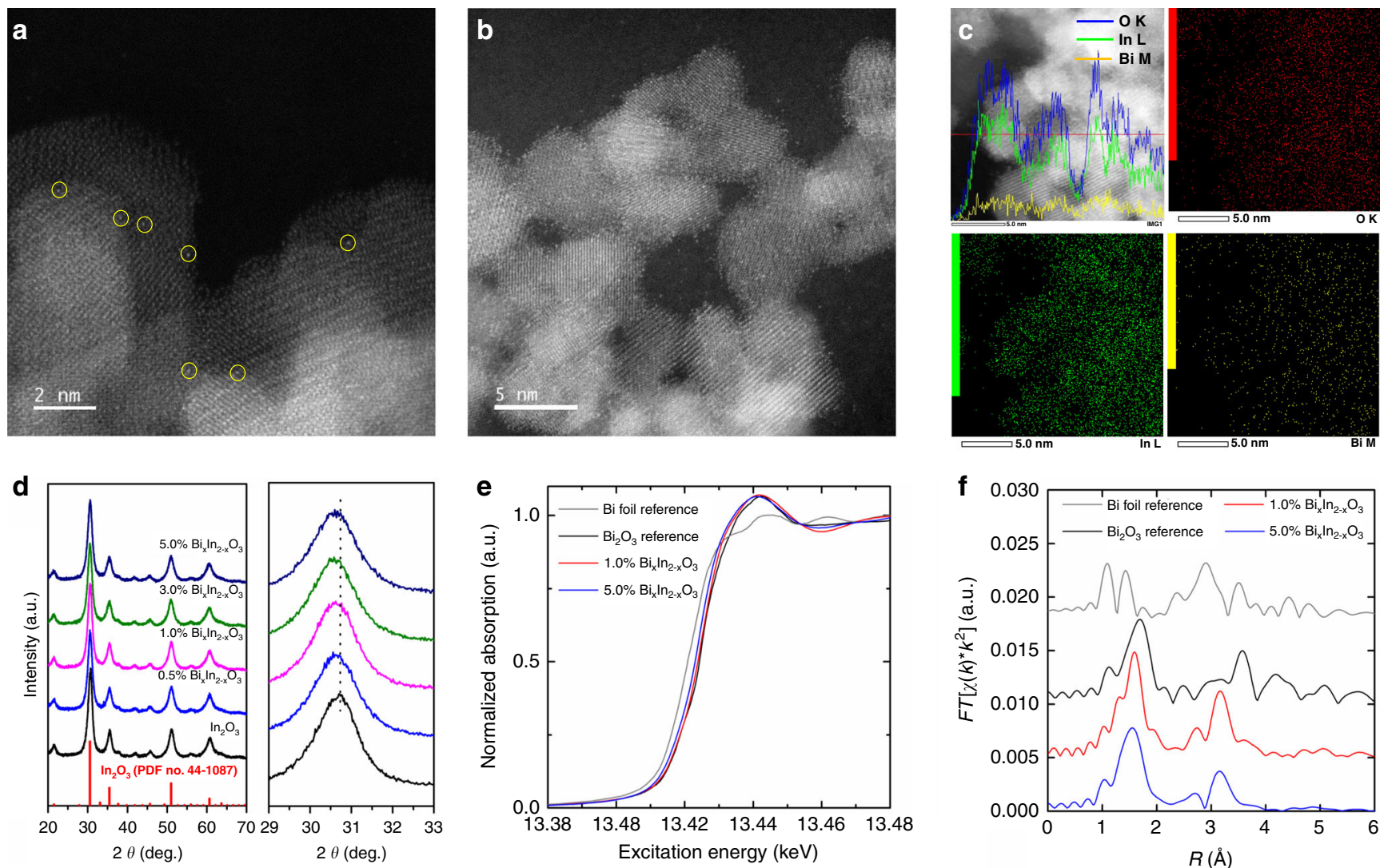

Fig. 1 Structural characterizations of single-site $\mathbf{B i}^{\mathbf{3}+}$ substituted $\mathbf{B i}_{\mathbf{x}} \mathbf{I n}_{\mathbf{2 - x}} \mathbf{O}_{\mathbf{3}}$. a Aberration-corrected $\mathrm{STEM}$ image of $1.0 \% \mathrm{Bi}_{x} \mathrm{In}{ }_{2-x} \mathrm{O}_{3}$ nanocrystals. b Aberration-corrected STEM image of $5.0 \% \mathrm{Bi}_{x} \mathrm{In}_{2-x} \mathrm{O}_{3}$ nanocrystals. c EDS mapping profiles of $5.0 \% \mathrm{Bi}_{x} \mathrm{In}_{2-x} \mathrm{O}_{3}$ along the indicated red line. $\mathbf{d} \mathrm{PXRD}$

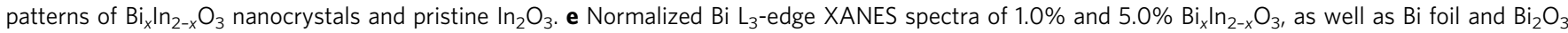
references. $\mathbf{f} \mathrm{k}^{3}$-Weighted $\mathrm{Bi} \mathrm{L}_{3}$-edge Fourier-transform EXAFS spectra of $1.0 \%$ and $5.0 \% \mathrm{Bi}_{x} \mathrm{In}_{2-x} \mathrm{O}_{3}$, as well as $\mathrm{Bi}_{\text {foil }}$ and $\mathrm{Bi}_{2} \mathrm{O}_{3}$ references.

evidence for the lack of $\mathrm{Bi}^{0}$ (Supplementary Fig. 5). Possibly EPR for semiconductors with high populations of [O]v occupied by electrons either does not exist or the existence of electronically degenerate ground states with fast electron relaxation and line broadening creates EPR silence. Maybe also the $[\mathrm{O}] \mathrm{v}$ are devoid of trapped electrons or are doubly filled and hence diamagnetic and EPR silent. Further studies, such as 4 probe Van Der Paaw electrical conductivity measurements, are necessary to fully elucidate the conduction electron model.

Synchrotron radiation-based X-ray absorption spectroscopy (XAS) was further used to obtain information regarding the local structural environment of these distributed $\mathrm{Bi}$ sites. The $\mathrm{Bi}$ $\mathrm{L}_{3}{ }^{-}$edge X-ray absorption near-edge structure (XANES) spectra in Fig. 1e reveal visible similarities between the $1.0 \%$ and $5.0 \%$ $\mathrm{Bi}_{x} \mathrm{In}_{2-x} \mathrm{O}_{3}$ sample spectra and that of the $\mathrm{Bi}_{2} \mathrm{O}_{3}$ reference. These similarities are to be expected, given that $\mathrm{Bi}$ atoms in both $\mathrm{Bi}_{2} \mathrm{O}_{3}$ and $\mathrm{Bi}_{x} \mathrm{In}_{2-x} \mathrm{O}_{3}$ lattices are expected to be octahedrally coordinated by oxygen atoms, leading to similarities in their structural and electronic properties. The Fourier-transformed $\mathrm{Bi}_{3}$-edge extended X-ray absorption fine structure (EXAFS) spectra are presented in Fig. 1f. The similar positions of the $\mathrm{Bi}-\mathrm{O}$ peak positions suggest that these bonds lengths in the $\mathrm{Bi}_{x} \mathrm{In}_{2-x} \mathrm{O}_{3}$ samples are similar to those in the $\mathrm{Bi}_{2} \mathrm{O}_{3}$ reference. In stark contrast, though, the observed $\mathrm{Bi}-\mathrm{M}$ peaks appear at distinctly different positions in the $\mathrm{Bi}_{x} \mathrm{In}_{2-x} \mathrm{O}_{3}$ spectra, revealing a distinct structural difference relative to the $\mathrm{Bi}_{2} \mathrm{O}_{3}$ reference. In order to more accurately quantify these differences in bond length and structure, the spectra were also fitted to extract key structural parameter values (Supplementary Fig. 6 and Supplementary
Table 2). The resulting Bi-In bond lengths in the $\mathrm{Bi}_{x} \mathrm{In}_{2-x} \mathrm{O}_{3}$ samples are shorter than those found in the pristine $\mathrm{Bi}_{2} \mathrm{O}_{3}$ lattice, though slightly longer than those observed in the pristine $\operatorname{In}_{2} \mathrm{O}_{3}$ lattice. Relatively larger Debye-Waller coefficient values for the $\mathrm{Bi}-\mathrm{O}$ peaks in $\mathrm{Bi}_{x} \mathrm{In}_{2-x} \mathrm{O}_{3}$ samples were also observed, reflecting a broader range of constituent $\mathrm{Bi}-\mathrm{O}$ bond lengths.

$\mathrm{CO}_{2}$ hydrogenation performance. The photocatalytic $\mathrm{CO}_{2}$ hydrogenation activity of $\mathrm{Bi}_{x} \mathrm{In}_{2-x} \mathrm{O}_{3}$ nanocrystals was evaluated in a batch reactor under simulated solar light irradiation and using a 1:1 ratio of $\mathrm{CO}_{2}$ and $\mathrm{H}_{2}$ gases. In these experiments, the RWGS reaction (i.e., $\mathrm{CO}_{2}+\mathrm{H}_{2} \rightarrow \mathrm{CO}+\mathrm{H}_{2} \mathrm{O}$ ) led to $\mathrm{CO}$ being the sole product detected. The $\mathrm{CO}$ production rates revealed that $1.0 \% \mathrm{Bi}_{x} \mathrm{In}_{2-x} \mathrm{O}_{3}$ was more active than $\mathrm{In}_{2} \mathrm{O}_{3}$ by approximately three orders of magnitude (Fig. 2a), with an impressive peak rate of $8000 \mu \mathrm{mol} \mathrm{g}^{-1} \mathrm{~h}^{-1}$ for its first run, as compared to just 35 $\mu \mathrm{mol} \mathrm{g}-1 \mathrm{~h}^{-1}$ for pristine $\operatorname{In}_{2} \mathrm{O}_{3}$. The estimated turnover frequency (TOF) of $\mathrm{In}_{2} \mathrm{O}_{3}$ and $1.0 \% \mathrm{Bi}_{x} \mathrm{In}_{2-x} \mathrm{O}_{3}$ is $0.42 \mathrm{~h}^{-1}$ and $93.6 \mathrm{~h}^{-1}$, respectively (Supplementary Note), implying that substituting $\mathrm{Bi}$ atoms into $\mathrm{In}_{2} \mathrm{O}_{3}$ nanocrystals significantly enhanced the photocatalytic activity towards $\mathrm{CO}_{2}$ hydrogenation. Remarkably, this boost in catalytic activity was much more dramatic than that observed in analogous hydroxylated systems (i.e., $\mathrm{Bi}_{x} \mathrm{In}_{2-}$ $\left.{ }_{x} \mathrm{O}_{3}(\mathrm{OH})_{y}\right)^{30}$, thereby suggesting a distinct and potent mechanism of catalytic activity enhancement in $\mathrm{Bi}_{x} \mathrm{In}_{2-x} \mathrm{O}_{3}$. Furthermore, such a $\mathrm{CO}$ production rate is much higher than some of the most active noble metal decorated photocatalysts (Supplementary Table 3). In addition, the $1.0 \% \mathrm{Bi}_{x} \mathrm{In}_{2-x} \mathrm{O}_{3}$ was very stable, exhibiting a 
a
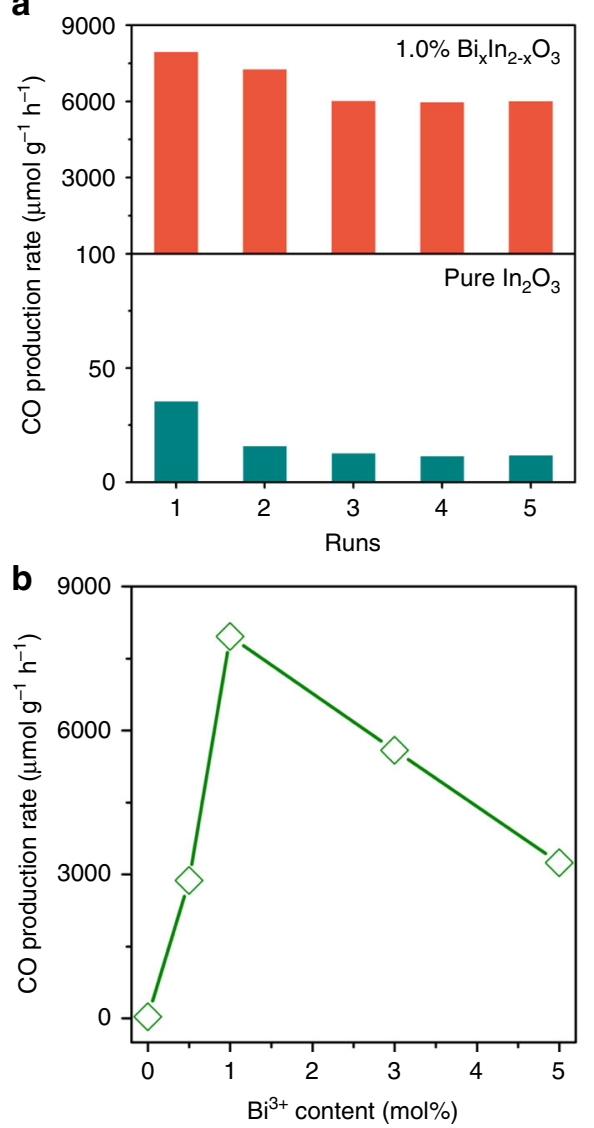

C

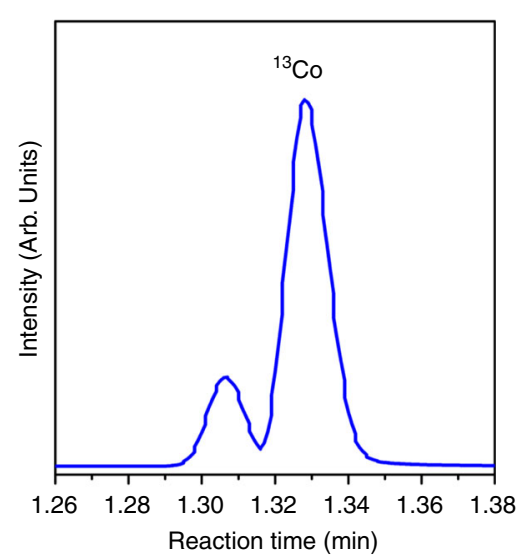

d 1.6

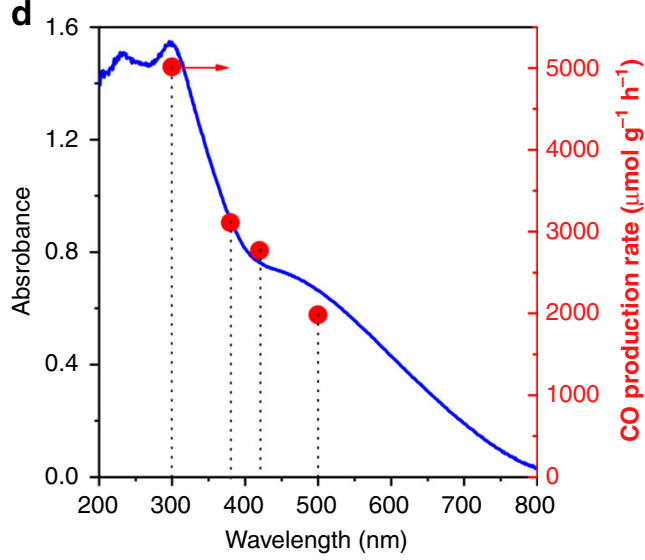

Fig. 2 Photocatalytic performance in the batch reactor. a $\mathrm{CO}$ rate of pristine $\ln _{2} \mathrm{O}_{3}$ (down) and $1.0 \% \mathrm{Bi}_{x} \ln _{2-x} \mathrm{O}_{3}$ nanocrystals (up) in catalyzing hydrogenation of $\mathrm{CO}_{2}$ under illumination. $\mathbf{b} \mathrm{CO}$ rate as a function of $\mathrm{Bi}^{3+}$ content for various $\mathrm{Bi}_{x} \mathrm{In}_{2-x} \mathrm{O}_{3}$ nanocrystals. c GC-MS plot of ${ }^{13} \mathrm{CO}$ produced from ${ }^{13} \mathrm{CO}_{2}$ over $1.0 \% \mathrm{Bi}_{x} \mathrm{In}_{2-x} \mathrm{O}_{3}$ nanocrystals. $\mathbf{d} \mathrm{CO}$ rate as a function of absorption cutoff filter wavelength for $1.0 \% \mathrm{Bi}_{x} \mathrm{In}_{2-x} \mathrm{O}_{3}$ nanocrystals.

CO production rate that was still roughly 600 times greater than the $11 \mu \mathrm{mol} \mathrm{g}-1 \mathrm{~h}^{-1}$ exhibited by pristine $\operatorname{In}_{2} \mathrm{O}_{3}$ under the same experimental conditions. In both cases, the $\mathrm{CO}$ production rate was observed to decrease over the course of five consecutive runs.

The actual bulk reaction temperature for $\operatorname{In}_{2} \mathrm{O}_{3}$ and $\mathrm{Bi}_{x} \mathrm{In}_{2-x} \mathrm{O}_{3}$ tested by infrared camera is about 70 and $115^{\circ} \mathrm{C}$ (Supplementary Fig. 7), respectively. The relatively low thermal energy supplied by solar light indicates the limited contribution of photothermal effect on the photocatalytic RWGS reaction. As an endothermic reaction, the rate of the RWGS is expected increase quite rapidly as a function of temperature. According to the Arrhenius Law, the rate should approximately double for every $10^{\circ} \mathrm{C}$ increase in temperature. Thus, we would expect the reaction rate to increase by a factor of 22.5 , assuming that the bulk temperature of the catalyst accurately reflects the temperature of the catalytically active sites. Based on the rate of pristine $\operatorname{In}_{2} \mathrm{O}_{3}$ (i.e., $35 \mu \mathrm{mol} \mathrm{g}-1 \mathrm{~h}^{-1}$ ), this would result in a rate increase to about $788 \mu \mathrm{mol} \mathrm{g}^{-1} \mathrm{~h}^{-1}$ and account for about $10 \%$ of the observed activity increase, thereby suggesting the existence of a significant photochemical effect. Notably, the marked increase in $\mathrm{CO}$ production rate upon substituting single-site $\mathrm{Bi}$ atoms into $\mathrm{In}_{2} \mathrm{O}_{3}$ was highly dependent on the concentration of $\mathrm{Bi}$ atoms (Fig. 2b). Meanwhile, isotopically labeled ${ }^{13} \mathrm{CO}_{2}$ experiment confirmed that $\mathrm{CO}$ was the unequivocal product from photocatalytic $\mathrm{CO}_{2}$ hydrogenation (Fig. 2c).

We also investigated the dependence of the $\mathrm{CO}$ production rate on the wavelength of light, to demonstrate the $\mathrm{CO}_{2}$ hydrogenation proceeds mainly through a photocatalytic process. As seen in the action spectra shown in Fig. $2 \mathrm{~d}$ and Supplementary Fig. 8, the production rate of $\mathrm{CO}$ monotonically decreased with longer wavelengths of the light, which correlates with the optical absorption spectrum of pristine $\mathrm{In}_{2} \mathrm{O}_{3}$ and $\mathrm{Bi}_{x} \mathrm{In}_{2-x} \mathrm{O}_{3}$ catalysts. It should also be mentioned that the $\mathrm{CO}$ production rate remained at about $2000 \mu \mathrm{mol} \mathrm{g}-1 \mathrm{~h}^{-1}$ on $1.0 \% \mathrm{Bi}_{x} \mathrm{In}_{2-x} \mathrm{O}_{3}$, even when a $500 \mathrm{~nm}$ cutoff filter was applied, thus implying that $\mathrm{Bi}_{x} \mathrm{In}_{2-x} \mathrm{O}_{3}$ nanocrystals can function as broadband, green photocatalysis for harvesting solar energy.

In light of the promising performance of $\mathrm{Bi}_{x} \mathrm{In}_{2-x} \mathrm{O}_{3}$ nanocrystals towards gas-phase $\mathrm{CO}_{2}$ hydrogenation, this new catalyst was also studied for solar methanol production in a flow reactor at $230{ }^{\circ} \mathrm{C}$, both with and without light irradiation. As shown in Supplementary Fig. 9, all catalysts exhibited similarly low CO and $\mathrm{CH}_{3} \mathrm{OH}$ production rates under purely thermal conditions; however, a remarkable enhancement in the production rates of $\mathrm{CO}$ and $\mathrm{CH}_{3} \mathrm{OH}$ was obtained on changing from dark to light conditions. In this case, pristine $\mathrm{In}_{2} \mathrm{O}_{3}$ exhibited $\mathrm{CO}$ and $\mathrm{CH}_{3} \mathrm{OH}$ production rates of 312 and $82 \mu \mathrm{mol} \mathrm{g}^{-1} \mathrm{~h}^{-1}$, respectively (Fig. 3a, b). In comparison, the single-site $\mathrm{Bi}_{x} \mathrm{In}_{2-x} \mathrm{O}_{3}$ samples exhibited much better activities for both $\mathrm{CO}$ and $\mathrm{CH}_{3} \mathrm{OH}$ production, with $1.0 \% \mathrm{Bi}_{x} \mathrm{In}_{2-x} \mathrm{O}_{3}$ exhibiting the highest $\mathrm{CO}$ and $\mathrm{CH}_{3} \mathrm{OH}$ production rates of $918 \mu \mathrm{mol} \mathrm{g}^{-1} \mathrm{~h}^{-1}$ and $158 \mu \mathrm{mol} \mathrm{g}^{-1} \mathrm{~h}^{-1}$, respectively. Overall, the measured activities of the $\mathrm{Bi}_{x} \operatorname{In}_{2-x} \mathrm{O}_{3}$ samples were highly dependent on $\mathrm{Bi}$ content and showed a volcano-shaped trend. The volcano trend of the activity towards $\mathrm{CO}_{2}$ hydrogenation versus the extent of $\mathrm{In}^{3+}$ substitution by the larger, more electronegative, $6 \mathrm{~s}^{2}$ stereochemically active lone-pair containing $\mathrm{Bi}^{3+}$, can be attributed to a subtle interplay of 

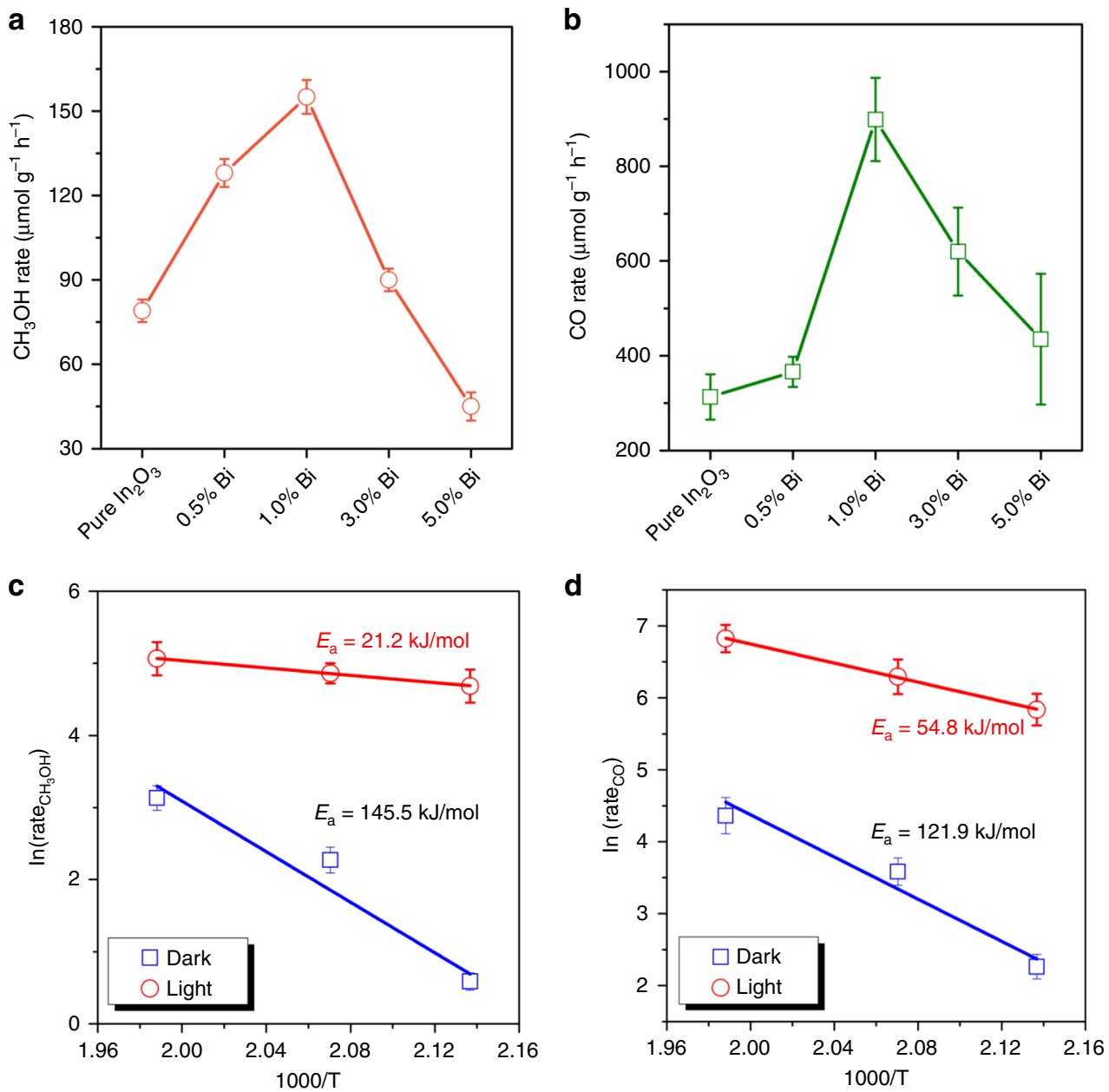

Fig. 3 Catalytic performance in the flow reactor with and without light irradiation. a $\mathrm{CH}_{3} \mathrm{OH}$ production rates as a function of $\mathrm{Bi}^{3+}$ content under light irradiation and at $230^{\circ} \mathrm{C}$. $\mathbf{b ~ C O}$ production rates as a function of $\mathrm{Bi}^{3+}$ content under light irradiation and at $230^{\circ} \mathrm{C}$. $\mathbf{c}$ Arrhenius plots for $\mathrm{CH}_{3} \mathrm{OH}$ production rates of $1.0 \% \mathrm{Bi}_{x} \mathrm{In}_{2-x} \mathrm{O}_{3}$ with and without solar irradiation. $\mathbf{d}$ Arrhenius plots for $\mathrm{CO}$ production rates of $1.0 \% \mathrm{Bi}_{x} \mathrm{In}_{2-x} \mathrm{O}_{3}$ with and without solar irradiation.

numerous and competing intertwined properties: chemical effects (e.g., influence of surface Lewis acidity and basicity of In-O-In, In-O-Bi, $\mathrm{Bi}-\mathrm{O}-\mathrm{Bi}$ sites on $\mathrm{CO}_{2}-\mathrm{H}_{2}$ adsorption, activation, reaction processes) and physical effects (e.g., photogenerated electron and hole charge-separation and charge-trapping by bismuth and oxygen vacancy mid-gap states).

The $\mathrm{CH}_{3} \mathrm{OH}$ and $\mathrm{CO}$ production rates of $\mathrm{Bi}_{x} \mathrm{In}_{2-x} \mathrm{O}_{3}$ nanocrystals showed negligible deactivation, even after $50 \mathrm{~h}$ of continuous testing under light irradiation at $230{ }^{\circ} \mathrm{C}$ (Supplementary Fig. 10a), suggesting their excellent catalytic stability. The recorded XRD patterns, TEM images and XPS spectra (Supplementary Fig. 10b-d) for the spent $\mathrm{Bi}_{x} \mathrm{In}_{2-x} \mathrm{O}_{3}$ photocatalysts after $50 \mathrm{~h}$ of reaction demonstrate that, except for a slight increase in particle size, the phase and oxidation states of the nanocrystals were well maintained, confirming their favorable structural stability.

To obtain more information on the origin of the activity enhancement under flow reaction conditions, activity tests were also conducted at lower reaction temperatures, beginning where products can be observed $\left(130,195\right.$, and $\left.210^{\circ} \mathrm{C}\right)$, with and without light irradiation (Supplementary Fig. 11). The drastic activity difference between dark and light conditions lend further support confirmed the contribution of the photochemical effect on $\mathrm{CO}$ and $\mathrm{CH}_{3} \mathrm{OH}$ production. Moreover, based on the Arrhenius plots for $1.0 \% \mathrm{Bi}_{x} \mathrm{In}_{2-x} \mathrm{O}_{3}$, the apparent activation energy for the $\mathrm{CO}$ and $\mathrm{CH}_{3} \mathrm{OH}$ photochemical processes are much lower than the thermochemical ones (Fig. 3c, d), reflecting the solar advantage for the excited-state reaction pathway relative to the ground state pathway ${ }^{31}$.

Photocatalytic reaction pathway. The photocatalytic $\mathrm{CO}_{2}$ hydrogenation reaction involves photon-absorption, electronhole separation, and $\mathrm{CO}_{2}$ adsorption/activation processes. The first two steps are closely related to the intrinsic nature of the photocatalyst, while the third is highly dependent on the gas-solid interface. A significant red shift occurs in the absorption edge of the UV-Vis spectra for all $\mathrm{Bi}_{x} \mathrm{In}_{2-x} \mathrm{O}_{3}$ samples (Fig. 4a), along with an enhanced tail above $440 \mathrm{~nm}$, which grows with $\mathrm{Bi}^{3+}$ content and is accompanied by a change in color from cream to rust (Supplementary Fig. 12). This is consistent with the simulated band structures that show the introduction of $\mathrm{Bi}^{3+}$ can leads to the formation of mid-gap states in the bandgap of $\operatorname{In}_{2} \mathrm{O}_{3}$ (Fig. 4b, c). The total density of states (DOS) and partial density of states (PDOS) (Supplementary Fig. 13) can further reveal that the substitution of $\mathrm{Bi}$ at the In site induces mid-gap energy states with $\mathrm{Bi} 6 \mathrm{~s}$ states below the conduction band edge of $\mathrm{In}_{2} \mathrm{O}_{3}$ and is consistent with the reported results in this paper ${ }^{32-34}$.

To understand the photogenerated charge transfer mechanism, the room-temperature photoluminescence (PL) spectra of pristine $\mathrm{In}_{2} \mathrm{O}_{3}$ and $1.0 \% \mathrm{Bi}_{x} \mathrm{In}_{2-x} \mathrm{O}_{3}$ nanocrystals are shown in Fig. $4 \mathrm{~d}$. The pristine $\mathrm{In}_{2} \mathrm{O}_{3}$ nanocrystals exhibited a strong green emission 

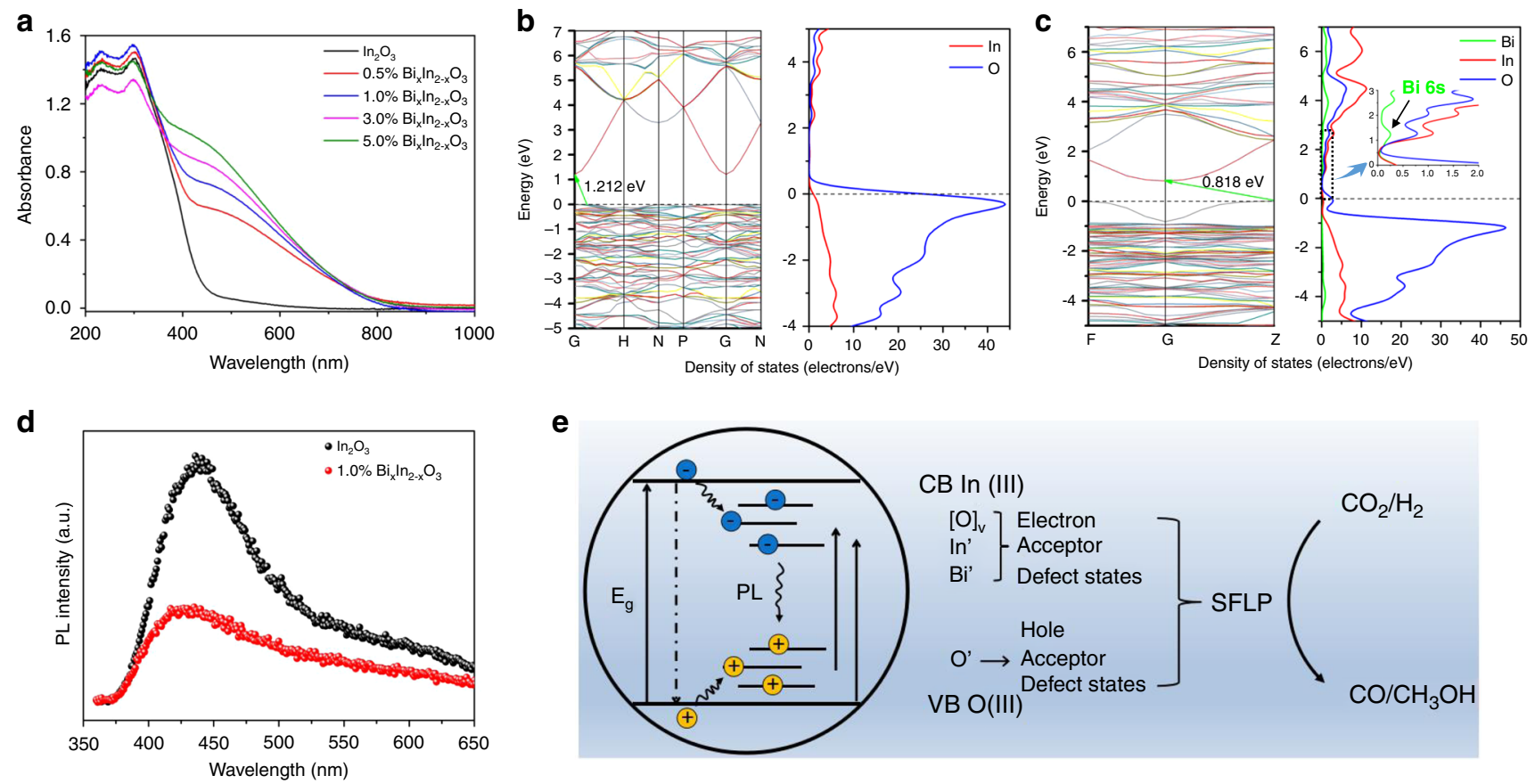

Fig. 4 Electronic structures of $\mathbf{B i}_{\mathbf{x}} \mathbf{I n}_{\mathbf{2 - x}} \mathbf{O}_{\mathbf{3}}$. a Diffuse reflectance spectra of pristine $\ln _{2} \mathrm{O}_{3}$ and various $\mathrm{Bi}_{x} \ln _{2-x} \mathrm{O}_{3}$ nanocrystals. $\mathbf{b}$ The simulated band structure and DOS plots of pristine $\mathrm{In}_{2} \mathrm{O}_{3}$. c The simulated band structure and DOS plots of $\mathrm{Bi}_{x} \mathrm{In}_{2-x} \mathrm{O}_{3}$ nanocrystals. $\mathbf{d}$ Room-temperature PL spectra of pristine $\mathrm{In}_{2} \mathrm{O}_{3}$ and $1.0 \% \mathrm{Bi}_{x} \mathrm{In}_{2-x} \mathrm{O}_{3}$ nanocrystals using an excitation wavelength of $325 \mathrm{~nm}$. e Schematic illustrating charge carrier recombination pathways on surface defects states (SFLPs) and enabling $\mathrm{CO}_{2}$ hydrogenation reactions.

peak centered at ca. $440 \mathrm{~nm}$, originating from the radiative recombination of photo-excited electrons trapped in mid-gap oxygen vacancy states with photogenerated holes in the valence band ${ }^{35}$. The existence of oxygen vacancies is further evidenced by the $\mathrm{O} 1 \mathrm{~s}$ core level XPS spectra (Supplementary Fig. 14). In contrast, the incorporation of single-site $\mathrm{Bi}$ into $\mathrm{In}_{2} \mathrm{O}_{3}$ leads to weakening and broadening of the PL emission peak. This can be explained in two ways. One is that the substitutional $\mathrm{Bi}^{3+}$ slightly decreases the concentration of oxygen vacancies (Supplementary Fig. 15), which would decrease the intensity due to electron-hole radiative recombination. Alternatively, the substituted $\mathrm{Bi}^{3+}$ states lying below the conduction band of $\operatorname{In}_{2} \mathrm{O}_{3}$ could also act as traps capturing photo-excited electrons and inhibiting electron-hole recombination emission, resulting in lower PL emission. Thus, as illustrated in Fig. 4e, the substituted $\mathrm{Bi}^{3+}$ sites (denoted as $\mathrm{Bi}^{\prime}$ ), oxygen vacancies $[\mathrm{O}]$, coordinately unsaturated indium In' sites and oxygen $\mathrm{O}^{\prime}$ sites, exist as mid-gap defect states (comprising surface frustrated Lewis pairs, SFLPs) in the bandgap of $\mathrm{Bi}_{x} \mathrm{In}_{2-}$ ${ }_{x} \mathrm{O}_{3}$, can function as traps for photogenerated electrons and holes enabling the reaction between $\mathrm{CO}_{2} / \mathrm{H}_{2}{ }^{36,37}$. This results in the quenching of steady-state PL emission as well as a slight shortening of the average fluorescence lifetime from 120 to 110 ps, probed by time-resolved PL spectroscopy (Supplementary Fig. 16). Albeit small, this reduction of the fluorescence lifetime, suggests that, relative to $\mathrm{In}_{2} \mathrm{O}_{3}$, single-site $\mathrm{Bi}$ atoms can increase the occurrence of competitive non-radiative relaxation processes in $\mathrm{Bi}_{x} \mathrm{In}_{2-x} \mathrm{O}_{3}{ }^{38-40}$.

Apart from its effect on the electronic structure and charge transfer, single-site $\mathrm{Bi}^{3+}$ substitution is also expected to strengthen the adsorption-bonding-activating ability of $\mathrm{Bi}_{x} \mathrm{In}_{2-}$ ${ }_{x} \mathrm{O}_{3}$ toward $\mathrm{CO}_{2}$. The textural structure of $\mathrm{Bi}_{x} \mathrm{In}_{2-x} \mathrm{O}_{3}$ including surface area, pore volume and pore size show obvious improvements and could favor the adsorption of $\mathrm{CO}_{2}$ reactants (Supplementary Table 4 and Supplementary Fig. 17). With respect to the surface chemistry, $\mathrm{CO}_{2}$ can bond through its carbon atom and oxygen atoms to either the surface oxygen atoms, metal sites, or directly with the oxygen vacancies of metal oxides (Supplementary Fig. 18) ${ }^{41-43}$. To investigate the effect of $\mathrm{Bi}^{3+}$ substitution on the interaction between $\mathrm{CO}_{2}$ and $\mathrm{Bi}_{x} \mathrm{In}_{2-x} \mathrm{O}_{3}$ or pristine $\mathrm{In}_{2} \mathrm{O}_{3}$ nanocrystals, $\mathrm{CO}_{2}$ temperature-programmed desorption $\left(\mathrm{CO}_{2}\right.$-TPD) measurements were initially performed. As shown in Fig. $5 \mathrm{a}$, one broad desorption peak at around $100^{\circ} \mathrm{C}$, corresponding to physically adsorbed $\mathrm{CO}_{2}$, is observed for all $\mathrm{Bi}_{x} \mathrm{In}_{2-x} \mathrm{O}_{3}$ nanocrystals and pristine $\operatorname{In}_{2} \mathrm{O}_{3}$. A significant desorption peak is clearly observed at $256^{\circ} \mathrm{C}$ for pristine $\mathrm{In}_{2} \mathrm{O}_{3}$ and can be attributed to the chemical desorption of $\mathrm{CO}_{2}$ that is binding with oxygen vacancies to form bent $\mathrm{CO}_{2}{ }^{\delta-}$ species ${ }^{44}$. Since $\mathrm{Bi}^{3+}$ substitution results in fewer oxygen vacancies, this peak intensity gradually decreases with increased $\mathrm{Bi}^{3+}$ doping of $\mathrm{Bi}_{x} \mathrm{In}_{2-x} \mathrm{O}_{3}$ nanocrystals and shifts slightly to higher temperatures (as high as $275^{\circ} \mathrm{C}$ for $5.0 \% \mathrm{Bi}_{x} \mathrm{In}_{2-x} \mathrm{O}_{3}$ ), implying that the binding strength of $\mathrm{CO}_{2}$ and oxygen vacancies is remarkably enhanced. Moreover, weak desorption peaks at higher temperatures $\left(300\right.$ to $\left.600^{\circ} \mathrm{C}\right)$ were clearly observed for $\operatorname{In}_{2} \mathrm{O}_{3}$, and can be assigned to the decomposition of surface $\mathrm{HCO}_{3}{ }^{-}$and $\mathrm{CO}_{3}{ }^{2-}$ species ${ }^{45}$. After single-site $\mathrm{Bi}^{3+}$ substitution, typical desorption peaks can also be clearly identified and show a slight shift to higher temperatures, again indicating that these surface species are binding more strongly to the surface.

In situ diffuse reflectance infrared Fourier-transform spectroscopy (DRIFTS) experiments were further carried out to identify surface species. Figure $5 \mathrm{~b}$ show the transient evolution of the surface species during $\mathrm{CO}_{2}$ adsorption over $1.0 \% \mathrm{Bi}_{x} \mathrm{In}_{2-x} \mathrm{O}_{3}$ nanocrystals. The bands at 1510 and $1372 \mathrm{~cm}^{-1}$ are assigned to the asymmetric and symmetric OCO stretching modes of monodentate carbonates $\left(m-\mathrm{CO}_{3}{ }^{2-}\right)$. The features at 1549 and $1330 \mathrm{~cm}^{-1}$ are attributed to the asymmetric and symmetric OCO stretching modes of bidentate carbonates $\left(b-\mathrm{CO}_{3}{ }^{2-}\right)$. The bent $\mathrm{CO}_{2}{ }^{\delta-}$ species adsorbed at oxygen vacancy sites can be identified by two bands at 1596 and $1348 \mathrm{~cm}^{-1}$, corresponding to the asymmetric and symmetric stretching modes, respectively. The appearance of bands at $1625,1437,1390$, and $1222 \mathrm{~cm}^{-1}$ 

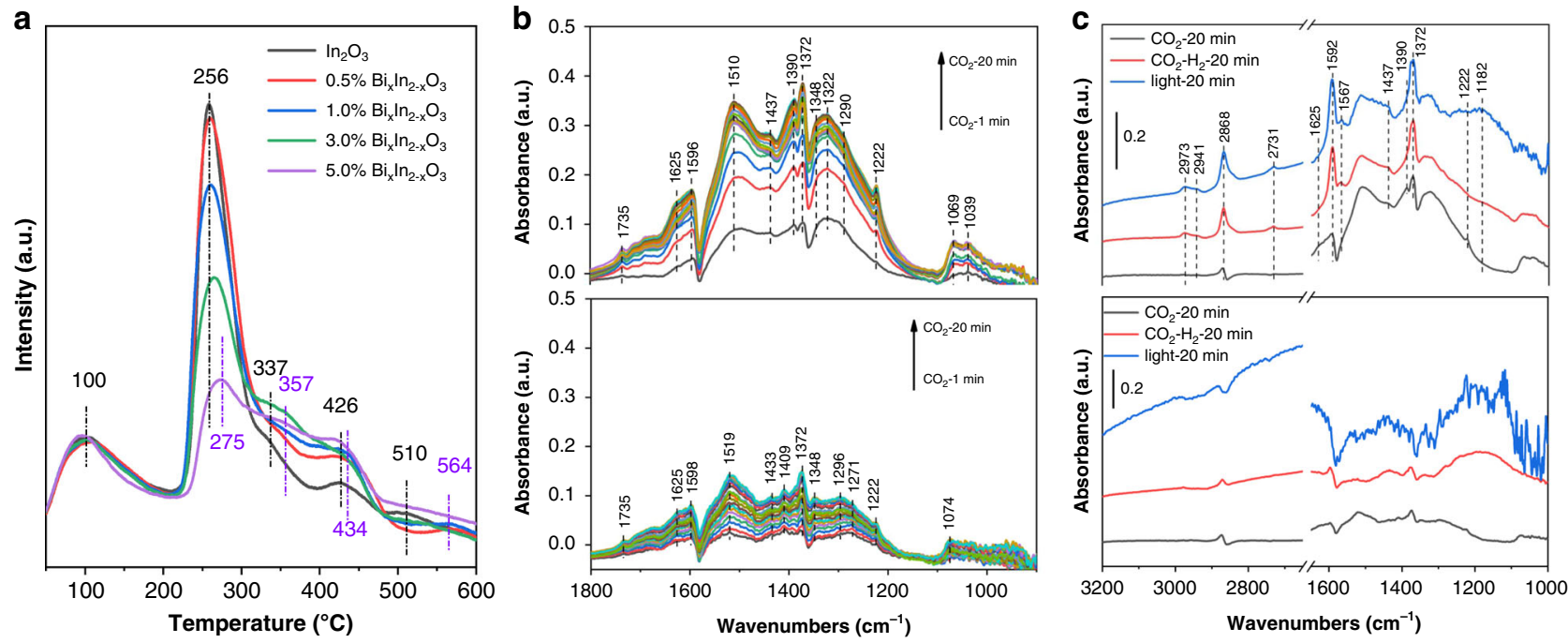

Fig. $\mathbf{5}$ In situ DRIFTS experiments of $\mathbf{C O}_{\mathbf{2}}$ adsorption and $\mathbf{C O}_{\mathbf{2}}$ hydrogenation. a $\mathrm{CO}_{2}-\mathrm{TPD}$ profiles. $\mathbf{b}$ In situ DRIFTS spectra for the adsorption of $\mathrm{CO}_{2}$ on $1.0 \% \mathrm{Bi}_{x} \mathrm{In}_{2-x} \mathrm{O}_{3}$ nanocrystals (up) and pure $\mathrm{In}_{2} \mathrm{O}_{3}$ (down). $\mathbf{c}$ In situ DRIFTS spectra of surface species under reaction conditions on $1.0 \% \mathrm{Bi}_{x} / \mathrm{n}_{2-x} \mathrm{O}_{3}$ nanocrystals (up) and pure $\ln _{2} \mathrm{O}_{3}$ (down).
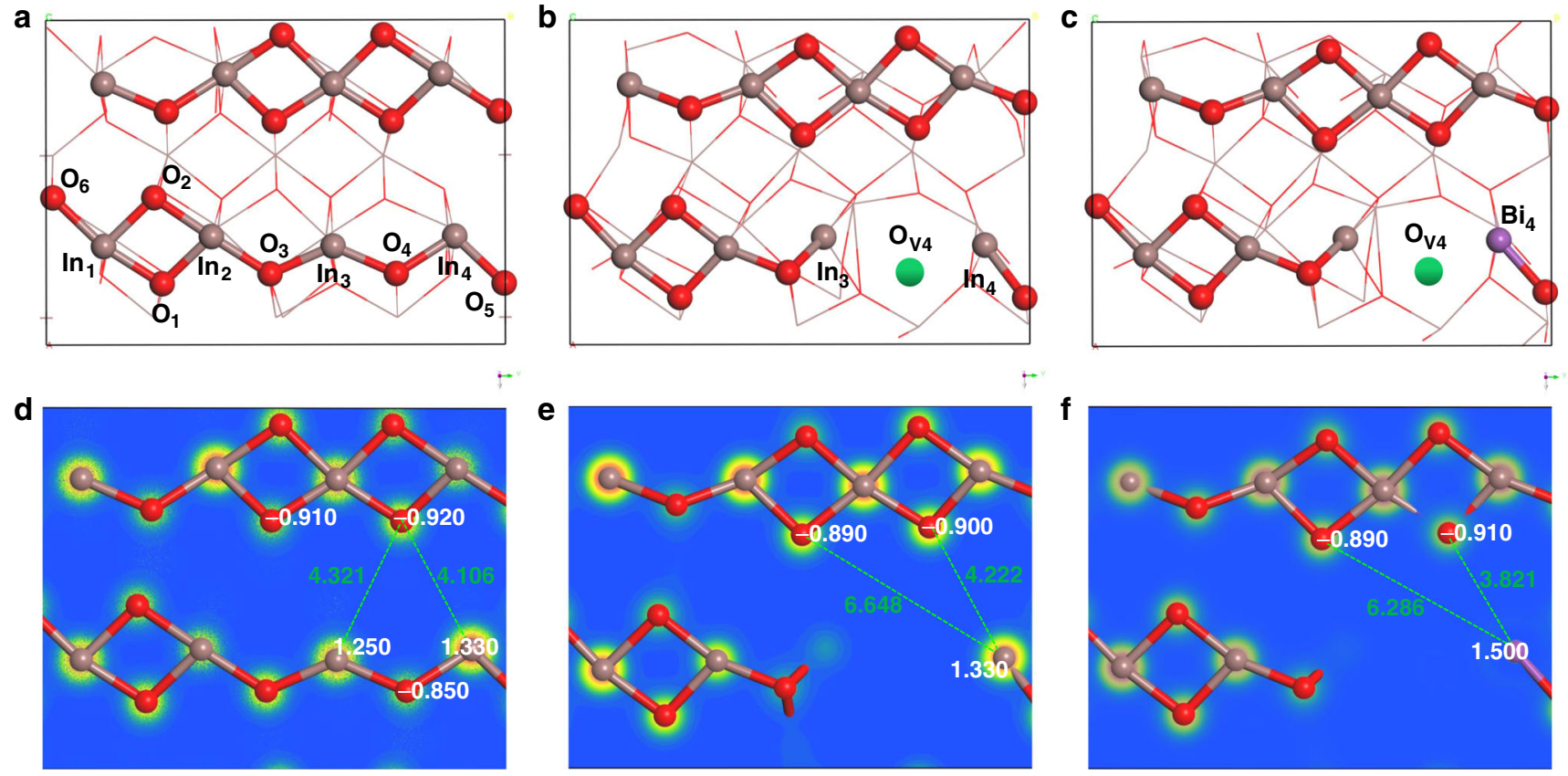

Fig. $\mathbf{6}$ Schematic images of the reactivity of SFLPs in single-site $\mathbf{B i}^{\mathbf{3}+}$ substituted $\mathbf{B i}_{\mathbf{x}} \mathbf{I n}_{\mathbf{2 - x}} \mathbf{O}_{\mathbf{3}} \cdot \mathbf{a}$ Optimized structure of perfect $\ln \mathrm{n}_{2} \mathrm{O}_{3}(110)$. $\mathbf{b}$ Optimized structure of defective $\ln _{2} \mathrm{O}_{3}$ (110) with one oxygen vacancy. c Optimized structure of $\mathrm{Bi}_{x} \mathrm{In}_{2-x} \mathrm{O}_{3}(110)$ with $\mathrm{Bi}^{3+}$ substitution. $\mathbf{d}$ Electron-density isosurface of perfect $\ln _{2} \mathrm{O}_{3}$ (110). e Electron-density isosurface of defective $\ln _{2} \mathrm{O}_{3}$ (110) with one oxygen vacancy. $\mathbf{f}$ Electron-density isosurface of $\mathrm{Bi}_{x} \mid \mathrm{n}_{2-x} \mathrm{O}_{3}(110)$ with $\mathrm{Bi}^{3+}$ substitution.

indicates the formation of bicarbonate species $\left(\mathrm{HCO}_{3}{ }^{-}\right)$. Moreover, a small amount of a linearly adsorbed $\mathrm{CO}_{2}$ species with bands appearing between 1000 and $1100 \mathrm{~cm}^{-1}$ can also be observed. Thus, via DRIFTS measurements, all the surface species observed during $\mathrm{CO}_{2}$-TPD measurements, $\mathrm{CO}_{3}{ }^{2-}, \mathrm{HCO}_{3}{ }^{-}$and $\mathrm{CO}_{2}{ }^{\delta-}$, were observed and identified on $\mathrm{Bi}_{x} \mathrm{In}_{2-x} \mathrm{O}_{3}$ nanocrystals. All these surface species can be observed on pristine $\operatorname{In}_{2} \mathrm{O}_{3}$; however, the peak intensities of these species are weaker than that on $\mathrm{Bi}_{x} \mathrm{In}_{2-x} \mathrm{O}_{3}$ nanocrystals, suggesting the improved $\mathrm{CO}_{2}$ adsorption-bonding-activating capacity after $\mathrm{Bi}^{3+}$ substitution.

Density functional theory (DFT) slab calculations were further carried out to unravel the promotion effect of $\mathrm{Bi}^{3+}$ substitution on $\operatorname{In}_{2} \mathrm{O}_{3}$. The perfect $\operatorname{In}_{2} \mathrm{O}_{3}(110)$ surface was initially selected as it has proven to be most thermodynamically stable ${ }^{20,46}$. The defective $\operatorname{In}_{2} \mathrm{O}_{3}$ (110) surface with an oxygen vacancy at the $\mathrm{O}_{4}$ site was then created owing to the more favorable ability for $\mathrm{CO}_{2}$ activation and hydrogenation ${ }^{19}$. Following then, we examined the possibility of $\mathrm{Bi}^{3+}$ substitution at the In site.

As shown in Fig. 6a, the perfect $\operatorname{In}_{2} \mathrm{O}_{3}(110)$ surface consists of chains of $\mathrm{In}$ and $\mathrm{O}$ atoms, with the numbering In and $\mathrm{O}$ atoms along the chain as repeating unit. The surface In and $\mathrm{O}$ in the chain are adjacent and contiguous to each other, forming a classic Lewis acid-base adjunct, whereas the unbonded $\mathrm{In}_{3}$ and $\mathrm{In}_{4}$ in the chain and $\mathrm{O}$ in the top layer show a distance of 4.106 and $4.312 \AA$, 
respectively, which may deliver SFLPs-like activity (Fig. 6d). However, the electronic interactions between $\mathrm{In}_{3}$ or $\mathrm{In}_{4}$ and its neighboring $\mathrm{O}_{4}$ will block the function of $\mathrm{In}_{3}-\mathrm{O}$ or $\mathrm{In}_{4}-\mathrm{O}$ pairs. Therefore, the removal of oxygen atom at the $\mathrm{O}_{4}$ site is the prerequisite to construct a pair of unbonded Lewis acid and base sites. When the $\mathrm{O}_{4}$ atom is removed, two $\mathrm{In}$ atoms $\left(\mathrm{In}_{3}\right.$ and $\left.\mathrm{In}_{4}\right)$ are coordinatively unsaturated and one oxygen vacancy $\left(\mathrm{O}_{\mathrm{V} 4}\right)$ is produced (Fig. 6b). However, in this case, only one $\mathrm{In}$ atom $\left(\operatorname{In}_{4}\right)$ locates at the surface while the other one $\left(\operatorname{In}_{3}\right)$ moves to the inner atomic layer. The surface $\mathrm{In}_{4}$ atom is found to be surrounded by two adjacent oxygen atoms, of which the $\mathrm{In}_{4}-\mathrm{O}$ with a distance of $4.222 \AA$ can construct a SFLPs site (Fig. 6e). We further investigated the effect of $\mathrm{Bi}^{3+}$ substitution at $\mathrm{In}_{4}$ site on the configuration and charge population (Fig. 6c, f). As compared to $\mathrm{In}_{4}$-O configuration, $\mathrm{Bi}_{4}$-O shows a shorter distance (3.821 $\AA$ ) but can still fall in the domain of solid SFLPs. On the other hand, the Bader charge calculations show that the related Lewis acid $\mathrm{Bi}^{3+}$ and Lewis base $\mathrm{O}^{2-}$ involve atomic local charges of +1.500 e and -0.910 e, respectively, which is higher than that of the $\mathrm{In}^{3+}$ and $\mathrm{O}^{2-}$ pair $(+1.300 \mathrm{e}$ and $-0.900 \mathrm{e})$. The larger charge difference between the Lewis acid and Lewis base pairs in the $\mathrm{Bi}_{x} \mathrm{In}_{2-x} \mathrm{O}_{3}$ compared with that of defective $\operatorname{In}_{2} \mathrm{O}_{3}$ would form more active Lewis acid-base pairs than the $\operatorname{In}_{2} \mathrm{O}_{3}$ pair can muster, and therefore could deliver a higher capability to activate $\mathrm{CO}_{2}$ molecules, consistent well with the DRIFTs and $\mathrm{CO}_{2}$-TPD results.

In the photo-excited state of a SFLPs system, the Lewis acidity and Lewis basicity have been shown to increase as compared with the ground state, thereby facilitating the photochemical $\mathrm{CO}_{2}$ hydrogenation, with a decrease in activation energy. To get more insight into the improved activity from $\mathrm{Bi}^{3+}$ substitution, in situ DRIFTS experiments were further performed under reaction conditions to detect the reaction intermediates and uncover the photocatalytic pathway in the $\mathrm{CO}_{2}$ hydrogenation process. As shown in Fig. $5 c$, when the $\mathrm{Bi}_{x} \mathrm{In}_{2-x} \mathrm{O}_{3}$ nanocrystals were exposed to the mixture of $\mathrm{CO}_{2}$ and $\mathrm{H}_{2}$ gases, bidentate formate ( ${ }^{*} \mathrm{HCOO}$ ), methoxy $\left({ }^{*} \mathrm{H}_{3} \mathrm{CO}\right)$ and carboxylate $\left({ }^{*} \mathrm{CO}_{2}\right){ }^{47}$, were the three principal intermediates observed from the transformation of bicarbonate and carbonate species, as evidenced by the decrease and disappearance of characteristic bands at 1510, 1390, and $1222 \mathrm{~cm}^{-1}$. The ${ }^{*}$ HCOO species can be linked to fingerprint modes at 2973 and $2731 \mathrm{~cm}^{-1}$, which correspond to a combination of the $\mathrm{CH}$ bending and OCO stretching modes ${ }^{47,48}$. The bands at 1592 and $1370 \mathrm{~cm}^{-1}$ can be assigned to the asymmetric and symmetric OCO stretching modes while that at $2868 \mathrm{~cm}^{-1}$ is attributed to the $\mathrm{CH}$ stretching mode of the same species ${ }^{47,49,50}$. The ${ }^{*} \mathrm{H}_{3} \mathrm{CO}$ species is signaled by diagnostic modes at 2941 and $2838 \mathrm{~cm}^{-1}$ that are assigned to the $\mathrm{CH}_{3}$ stretching modes and the band at $1182 \mathrm{~cm}^{-1}$ is attributed to the CO stretching mode of bridged methoxide species ${ }^{47,48,51}$. In addition to ${ }^{*} \mathrm{HCOO}$ and ${ }^{*} \mathrm{H}_{3} \mathrm{CO},{ }^{*} \mathrm{CO}_{2}$ species were also observed, with bands at 1567 and $1379 \mathrm{~cm}^{-1}$ that can be associated with the OCO stretching modes. Under light irradiation, all intermediates showed an increase in band intensity (Supplementary Fig. 19), thereby confirming the photochemical effect of $\mathrm{CO}_{2}$ hydrogenation, and is consistent with the activity results. From these DRIFT results, $\mathrm{CO}_{2}$ hydrogenation over $\mathrm{Bi}_{x} \mathrm{In}_{2-x} \mathrm{O}_{3}$ may proceed via two major reaction pathways featured by both formate intermediate and $\mathrm{CO}$ intermediate, which has been well established for the $\operatorname{In}_{2} \mathrm{O}_{3-x}(\mathrm{OH})_{y}$ systems ${ }^{12}$. In the case of pristine $\mathrm{In}_{2} \mathrm{O}_{3}$ (Fig. $5 \mathrm{c}$ and Supplementary Fig. 20), ${ }^{*} \mathrm{HCOO}$ and ${ }^{*} \mathrm{H}_{3} \mathrm{CO}$ species of virtually insignificant intensity were observed for $\mathrm{CO}_{2}$ hydrogenation, and light irradiation resulted in much noisier peaks. This further indicates the moderate catalytic performance of pristine $\operatorname{In}_{2} \mathrm{O}_{3}$ and the significant promotion effect resulting from single-site $\mathrm{Bi}^{3+}$ substitution. To corroborate these experimental observations, free energy profiles for $\mathrm{CO}_{2}$ hydrogenation via the proposed RWGS pathway over $\mathrm{Bi}_{x} \mathrm{In}_{2-x} \mathrm{O}_{3}$ and pristine $\mathrm{In}_{2} \mathrm{O}_{3}$ were calculated (Supplementary Fig. 21). It can be seen that the $\mathrm{H}_{2}$ dissociation into $\mathrm{H}^{*}$ on pristine $\mathrm{In}_{2} \mathrm{O}_{3}$ (defective type with one oxygen vacancy) is the rate-limiting step and endothermic with an activation energy barrier of $1.47 \mathrm{eV}$. Importantly, compared with pristine $\mathrm{In}_{2} \mathrm{O}_{3}$, the $\mathrm{Bi}_{x} \mathrm{In}_{2-x} \mathrm{O}_{3}$ exhibits a negative $\Delta G$ value of $-0.05 \mathrm{eV}$ for the $\mathrm{H}_{2}$ dissociation, which implies that the $\mathrm{H}_{2}$ dissociation into $\mathrm{H}^{*}$ on the surface of $\mathrm{Bi}_{x} \mathrm{In}_{2-x} \mathrm{O}_{3}$ is energetically favorable. This result indicates that the single-site $\mathrm{Bi}^{3+}$ substituted nanostructure has more active Lewis acid-base pairs than the $\mathrm{In}_{2} \mathrm{O}_{3}$ pair can muster, and therefore can strongly polarize $\mathrm{H}-\mathrm{H}$ bonds and dissociate $\mathrm{H}_{2}$ molecules into ${ }^{*} \mathrm{H}$. The proceeding hydrogenation reactions of $\mathrm{H}^{*}$ with $\mathrm{CO}_{2}$ on the surface of $\operatorname{In}_{2} \mathrm{O}_{3}$ and $\mathrm{Bi}_{x} \mathrm{In}_{2-x} \mathrm{O}_{3}$ are similar. However, benefiting from the favorable $\mathrm{H}_{2}$ dissociation, $\mathrm{Bi}_{x} \mathrm{In}_{2-x} \mathrm{O}_{3}$ shows a much-lowered reaction energy profile for $\mathrm{CO}$ and $\mathrm{H}_{2} \mathrm{O}$ formation than pristine $\mathrm{In}_{2} \mathrm{O}_{3}$.

\section{Discussion}

In summary, we have demonstrated a one-step solvothermal route towards atom-precise isomorphic substitution of $\mathrm{In}^{3+}$ in $\mathrm{In}_{2} \mathrm{O}_{3}$ by $\mathrm{Bi}^{3+}$ to generate $\mathrm{Bi}_{x} \mathrm{In}_{2-x} \mathrm{O}_{3}$ materials with broadspectrum $\mathrm{UV}-\mathrm{V}$ is absorption. The incorporation of single-site $\mathrm{Bi}$ atoms in the $\mathrm{In}_{2} \mathrm{O}_{3}$ host lattice provides strong Lewis acid-base $\mathrm{Bi}^{3+}-\mathrm{O}^{2-}$ pairs to enhance $\mathrm{CO}_{2}$ adsorption and activation, resulting in distinctly enhanced reaction rates relative to those observed for pristine $\operatorname{In}_{2} \mathrm{O}_{3}$ and other indium oxide-based catalysts. The $\mathrm{Bi} 6 \mathrm{~s}^{2}$ lone pairs create mid-gap energy states, which can increase the harvesting of solar photons and favor the generation and separation of photo-induced charge carriers. Remarkably, single-site $\mathrm{Bi}^{3+}$-substituted $\mathrm{Bi}_{x} \mathrm{In}_{2-x} \mathrm{O}_{3}$ proves to be a highly efficient and stable photocatalyst, achieving an impressive $\mathrm{CO}$ production rate three orders of magnitude greater than that of pristine $\operatorname{In}_{2} \mathrm{O}_{3}$, with notable photoactivity towards solar methanol. In addition to increased activity catalytic sites, the greening of indium oxide by single-site bismuth atom substitution represents a new approach to $\mathrm{CO}_{2}$ photocatalyst engineering and is a further step towards the vision of a solar $\mathrm{CO}_{2}$ refinery.

\section{Methods}

Synthesis of $\mathbf{I n}_{\mathbf{2}} \mathbf{O}_{\mathbf{3}}$ and $\mathbf{B} \mathbf{i}_{\mathbf{x}} \mathbf{I n}_{\mathbf{2 - x}} \mathbf{O}_{\mathbf{3}}$. Pristine $\mathrm{In}_{2} \mathrm{O}_{3}$ nanocrystals were prepared via a simple solvothermal route. In a typical synthesis, $0.3 \mathrm{~g}$ of $\mathrm{In}\left(\mathrm{NO}_{3}\right)_{3} \bullet 4.5 \mathrm{H}_{2} \mathrm{O}$ was dissolved in $17 \mathrm{~mL}$ anhydrous dimethylformamide solution. After stirring for 30 min, the obtained homogeneous solution was transferred into a Teflon-lined stainless steel autoclave and then heated at $150{ }^{\circ} \mathrm{C}$ for $24 \mathrm{~h}$. After being cooled to room temperature, the light-yellow product was collected through centrifugation, washed with ethanol and water, and finally dried at $60^{\circ} \mathrm{C}$ in vacuum. $\mathrm{Bi}^{3+}$-substituted $\mathrm{In}_{2} \mathrm{O}_{3}$ nanocrystals were prepared using the same method employed for pristine $\mathrm{In}_{2} \mathrm{O}_{3}$, except that various amounts of $\mathrm{Bi}\left(\mathrm{NO}_{3}\right)_{3} \cdot 5 \mathrm{H}_{2} \mathrm{O}$ were added to the indium solution prior to solvothermal reaction.

Material characterizations. The content of $\mathrm{Bi}$ in $\mathrm{Bi}_{x} \mathrm{In}_{2-x} \mathrm{O}_{3}$ was determined using an inductively coupled plasma mass spectroscopy (ICP-MS) instrument (Optima 7300 DV). Powder X-ray diffraction (PXRD) was performed on a Bruker D2Phaser X-ray diffractometer, using $\mathrm{Cu} \mathrm{Ka}$ radiation at $30 \mathrm{kV}$. X-ray photoelectron spectroscopy (XPS) was performed using a PerkinElmer Phi 5500 ESCA spectrometer in an ultrahigh vacuum chamber with a base pressure of $1 \times 10^{-9}$ Torr. The spectrometer used an $\mathrm{Al} \mathrm{Ka} \mathrm{X-ray} \mathrm{source} \mathrm{operating} \mathrm{at} 15 \mathrm{kV}$ and $27 \mathrm{~mA}$. The samples were coated onto carbon tape prior to analysis and all results were calibrated to C1s $284.5 \mathrm{eV}$. EPR spectra were obtained at room temperature and $77 \mathrm{~K}$ using a Bruker A-300-EPR X-band spectrometer. Transmission electron microscopy (TEM) measurements were conducted using a JEM-2010 microscope working at $200 \mathrm{kV}$. The double spherical aberration-corrected scanning transmission electron microscope (STEM) images were obtained on an FEI Themis Z instrument. X-ray absorption spectra were collected at the BL14W beamline of the Shanghai Synchrotron Radiation Facility (SSRF). The storage ring of the SSRF was operated at $3.5 \mathrm{GeV}$ with a stable current of $200 \mathrm{~mA}$. Using a Si(111) double-crystal monochromator, the data collection was carried out in fluorescence mode using Lytle detector. All spectra were collected under ambient conditions. Diffuse reflectance spectra (DRS) of the powders were obtained for dry-pressed disk 
samples using a Cary 500 Scan Spectrophotometer (Varian, USA) over a range of 200 to $800 \mathrm{~nm}$. Barium sulfate $\left(\mathrm{BaSO}_{4}\right)$ was used as a reflectance standard. Roomtemperature photoluminescence (PL) spectra were measured on an FL/FS 920 (Edinburgh Instruments) system equipped with a $450 \mathrm{~W}$ Xe arc lamp as the excitation source and a red sensitive Peltier element-cooled Hamamatsu R2658 PMT as the detector. Time-resolved fluorescence decay spectra were recorded on the Delta Pro (HORIBA instruments) using a $357 \mathrm{~nm}$ laser as the excitation source. BET surface area analyses were performed on an ASAP2020 M apparatus (Micromeritics Instrument Corp., USA) with the samples degassing in vacuum at $110^{\circ} \mathrm{C}$ for $10 \mathrm{~h}$ and then measuring at $77 \mathrm{~K}$. The $\mathrm{CO}_{2}$ temperature-programmed desorption $\left(\mathrm{CO}_{2}\right.$-TPD) measurements were carried out on AutoChem II 2920 Version. The density functional theory (DFT) calculations were performed using the Cambridge Sequential Total Energy Package (CASTEP) computational codes. During the geometry optimization, lattice parameters and atomic positions were optimized simultaneously. Based on the experimental data, we replaced one In with $\mathrm{Bi}$ in the cell as the $\mathrm{In}_{15} \mathrm{BiO}_{24}$ model and deleted one of the oxygen atom that were coordinating with $\mathrm{Bi}$ to establish one $\mathrm{In}_{15} \mathrm{BiO}_{23}\left(\mathrm{O}_{\text {Vacancy }}\right)$ model. For calculating the electronic structures and density of states, the geometry optimization of $\operatorname{In}_{2} \mathrm{O}_{3}$ and $\mathrm{In}_{15} \mathrm{BiO}_{23}\left(\mathrm{O}_{\text {Vacancy }}\right)$ were calculated by the PBE method within Generalized Gradient-corrected Approximation (GGA), using the exchange-correlation potential. The Vanderbilt ultrasoft pseudopotential with a cutoff energy of $380 \mathrm{eV}$ was used to ensure the precision of the results. Brillouin zone integration was represented using the K-point sampling scheme of $3 \times 3 \times 3$ Monkhorst-Pack scheme. The convergence tolerance for geometry optimization was selected with the differences in total energy $\left(5.0 \times 10^{-6} \mathrm{eV} /\right.$ atom $)$, the maximal ionic Hellmann-Feynman force $\left(1.0 \times 10^{-2} \mathrm{eV} \AA^{-1}\right)$, the stress tensor $\left(2.0 \times 10^{-2} \mathrm{GPa}\right)$, and the maximal displacement $\left(5.0 \times 10^{-4} \AA\right)$.

\section{Gas-phase $\mathrm{CO}_{2}$ hydrogenation tests. Batch reactions were conducted in a} custom-built $1.5 \mathrm{~mL}$ stainless steel batch reactor with a fused-silica viewport sealed with Viton O-rings. The reactor with $\sim 4.5 \mathrm{mg}$ of catalyst on a borosilicate film support was evacuated using an Alcatel dry pump prior to being purged with the reactant high-purity $\mathrm{H}_{2}$ reactant gas. After purging the reactor, it was filled with a 1:1 stoichiometric mixture of $\mathrm{H}_{2}(99.9995 \%)$ and $\mathrm{CO}_{2}(99.999 \%)$ until the total pressure reached $30 \mathrm{psi}$. The reactor was irradiated with a $300 \mathrm{~W}$ Xe lamp for a duration of $1 \mathrm{~h}$ without external heating. Product gases were analyzed using flame ionization and thermal conductivity detectors installed in a SRI-8610 gas chromatograph equipped with 3 in. Mole Sieve 13a and 6 in. Haysep D column. Isotopically labeled tracing experiments were performed using ${ }^{13} \mathrm{CO}_{2}(99.9$ at $\%$, Sigma-Aldrich). Isotope distributions in the product gases were measured using an Agilent 7890A gas chromatograph-mass spectrometer with a $60 \mathrm{~m}$ GS-carbon plot column, leading to the mass spectrometer. Flow experiments were carried out in a fixed-bed tubular reactor with $\sim 10 \mathrm{mg}$ of catalyst material being packed into a quartz tube and immobilized at both ends with quartz wool. The quartz tube had an inner diameter of $2 \mathrm{~mm}$ with a wall thickness of $0.5 \mathrm{~mm}$, and was placed into a groove carved out into a copper block. An OMEGA temperature controller was attached to two heating cartridges inserted into the copper block and a thermocouple was inserted into the quartz tube contacting the catalyst but covered by the quartz wool. A $300 \mathrm{~W}$ Xe arc lamp illuminated the catalyst plug at a measured intensity of $2 \mathrm{~W} \mathrm{~cm}^{-2} . \mathrm{CO}_{2}$ and $\mathrm{H}_{2}$ were flowed through with a 1:3 ratio $(1 \mathrm{sccm}$ $\mathrm{CO}_{2}, 3 \mathrm{sccm} \mathrm{H}_{2}$ ). The amounts of $\mathrm{CO}$ and $\mathrm{CH}_{3} \mathrm{OH}$ produced were determined using gas chromatography-mass spectrometry (GC-MS, 7890B and 5977A, Agilent) using a He carrier gas.

In situ DRIFT studies. The in situ DRIFTS measurements were performed to detect the surface intermediates over pristine $\operatorname{In}_{2} \mathrm{O}_{3}$ and $\mathrm{Bi}_{x} \mathrm{In}_{2-x} \mathrm{O}_{3}$ nanocrystals under reaction conditions. The spectra were collected using a Fourier-transform infrared spectroscopy spectrometer (Thermo, Nicolet 6700) equipped with an MCT detector. Before measurement, the catalyst was purged with $\mathrm{He}$ at $250^{\circ} \mathrm{C}$ for $2 \mathrm{~h}$. The catalyst was subsequently cooled down to $230^{\circ} \mathrm{C}$. The background spectrum with a resolution of $4 \mathrm{~cm}^{-1}$ was obtained at $230^{\circ} \mathrm{C}$ in $\mathrm{He}$ flow. Then the catalyst was exposed to a mixture of $\mathrm{CO}_{2}, \mathrm{H}_{2}$, and $\mathrm{He}\left(1 \mathrm{sccm} \mathrm{CO} \mathrm{CO}_{2}, 3 \mathrm{sccm} \mathrm{H} \mathrm{H}_{2}\right.$, and $16 \mathrm{sccm} \mathrm{He}$, respectively) in dark and light conditions for different times. The in situ DRIFT spectra were recorded by collecting 32 scans at $4 \mathrm{~cm}^{-1}$ resolutions.

Received: 27 July 2020; Accepted: 29 October 2020;

Published online: 30 November 2020

\section{References}

1. Dang, S. S. et al. Rationally designed indium oxide catalysts for $\mathrm{CO}_{2}$ hydrogenation to methanol with high activity and selectivity. Sci. Adv. 6, eaaz2060 (2020).

2. Wang, $\mathrm{M}$. et al. Oxygen vacancy generation and stabilization in $\mathrm{CeO}_{2-\mathrm{x}}$ by $\mathrm{Cu}$ introduction with improved $\mathrm{CO}_{2}$ photocatalytic reduction activity. ACS Catal. 9, 4573-4581 (2019).
3. Wang, W., Wang, S. P., Ma, X. B. \& Gong, J. L. Recent advances in catalytichydrogenation of carbon dioxide. Chem. Soc. Rev. 40, 3703-3727 (2011).

4. Jia, J. et al. Visible and near-infrared photothermal catalyzed hydrogenation of gaseous $\mathrm{CO}_{2}$ over nanostructured $\mathrm{Pd} @ \mathrm{Nb}_{2} \mathrm{O}_{5}$. Adv. Sci. 3, 1600189 (2016).

5. Meng, X. G. et al. Photothermal conversion of $\mathrm{CO}_{2}$ into $\mathrm{CH}_{4}$ with $\mathrm{H}_{2}$ over group VIII nanocatalysts: an alternative approach for solar fuel production. Angew. Chem. Int. Ed. 53, 11478-11482 (2014).

6. Chen, G. B. et al. Alumina-supported CoFe alloy catalysts derived from layered-double-hydroxide nanosheets for efficient photothermal $\mathrm{CO}_{2}$ hydrogenation to hydrocarbons. Adv. Mater. 29, 1704663 (2017).

7. Feng, K. et al. Cobalt plasmonic superstructures enable almost $100 \%$ broadband photon efficient $\mathrm{CO}_{2}$ photocatalysis. Adv. Mater. 32, 2000014 (2020).

8. Stephan, D. W. Frustrated Lewis pairs. J. Am. Chem. Soc. 137, 10018-10032 (2015).

9. Stephan, D. W. \& Erker, G. Frustrated Lewis pair chemistry: development and perspectives. Angew. Chem. Int. Ed. 54, 6400-6441 (2015).

10. Ma, Y. Y. et al. Semi-solid and solid frustrated Lewis pair catalysts. Chem. Soc. Rev. 47, 5541-5553 (2018).

11. Ghuman, K. K. et al. Illuminating $\mathrm{CO}_{2}$ reduction on frustrated Lewis pair surfaces: investigating the role of surface hydroxides and oxygen vacancies on nanocrystalline $\operatorname{In}_{2} \mathrm{O}_{3-\mathrm{x}}(\mathrm{OH})_{\mathrm{y}}$. Phys. Chem. Chem. Phys. 17, 14623-14635 (2015).

12. Yan, T. J. et al. Polymorph selection towards photocatalytic gaseous $\mathrm{CO}_{2}$ hydrogenation. Nat. Commun. 10, 2521-2530 (2019).

13. Wang, L. et al. Room-temperature activation of $\mathrm{H}_{2}$ by a surface frustrated Lewis pair. Angew. Chem. Int. Ed. 58, 9501-9505 (2019).

14. Wang, X. H. et al. Frustrated Lewis pairs accelerating $\mathrm{CO}_{2}$ reduction on oxyhydroxide photocatalysts with surface lattice hydroxyls as a solid-state proton donor. Adv. Funct. Mater. 28, 1804191-1804199 (2018).

15. Zhang, S. et al. Solid frustrated-Lewis-pair catalysts constructed by regulations on surface defects of porous nanorods of $\mathrm{CeO}_{2}$. Nat. Commun. 8, 15266-15277 (2017).

16. Wang, J. Y. et al. Variation in the $\operatorname{In}_{2} \mathrm{O}_{3}$ crystal phase alters catalytic performance toward the reverse water gas shift reaction. ACS Catal. 10, 3264-3273 (2020).

17. Wang, L. R. et al. $\mathrm{In}_{2} \mathrm{O}_{3}$ nanocrystals for $\mathrm{CO}_{2}$ fixation: atomic-level insight into the role of grain boundaries. iScience 16, 390-398 (2019).

18. Sun, K. H. et al. Hydrogenation of $\mathrm{CO}_{2}$ to methanol over $\mathrm{In}_{2} \mathrm{O}_{3}$ catalyst. $J$. CO2 Utiliz. 12, 1-6 (2015).

19. Ye, J. Y., Liu, C. J., Mei, D. H. \& Ge, Q. F. Active oxygen vacancy site for methanol synthesis from $\mathrm{CO}_{2}$ hydrogenation on $\mathrm{In}_{2} \mathrm{O}_{3}(110)$ : A DFT study. ACS Catal. 3, 1296-1306 (2013).

20. Ye, J. Y., Liu, C. J. \& Ge, Q. F. DFT study of $\mathrm{CO}_{2}$ adsorption and hydrogenation on the $\operatorname{In}_{2} \mathrm{O}_{3}$ surface. J. Phys. Chem. C. 116, 7817-7825 (2012).

21. Martin, O. et al. Indium oxide as a superior catalyst for methanol synthesis by $\mathrm{CO}_{2}$ hydrogenation. Angew. Chem. Int. Ed. 55, 6261-6265 (2016).

22. Gao, P. et al. Direct conversion of $\mathrm{CO}_{2}$ into liquid fuels with high selectivity over a bifunctional catalyst. Nat. Chem. 9, 1019-1024 (2017).

23. Wang, L. et al. Black indium oxide a photothermal $\mathrm{CO}_{2}$ hydrogenation catalyst. Nat. Commun. 11, 2432-2439 (2020).

24. Frei, M. S. et al. Atomic-scale engineering of indium oxide promotion by palladium for methanol production via $\mathrm{CO}_{2}$ hydrogenation. Nat. Commun. 10, 3377-3387 (2019).

25. Mohan, R. Green bismuth. Nat. Chem. 2, 336-336 (2010).

26. Gordon, R. B. \& Rutledge, J. W. Bismuth bronze from Machu Picchu, Peru. Science 223, 585-586 (1984).

27. Rohr, O. Bismuth-the new ecologically green metal for modern lubricating engineering. Ind. Lubr. Tribol. 54, 153-164 (2002).

28. Leng, M. Y. et al. Lead-free, blue emitting bismuth halide perovskite quantum dots. Angew. Chem. Int. Ed. 55, 1-6 (2016).

29. Ye, L. Q., Deng, Y., Wang, L., Xie, H. Q. \& Su, F. Y. Bismuth-based photocatalysts for solar photocatalytic carbon dioxide Conversion. ChemSusChem 12, 3671-3701 (2019).

30. Dong, Y. C. et al. Tailoring surface frustrated Lewis pairs of $\operatorname{In}_{2} \mathrm{O}_{3-\mathrm{x}}(\mathrm{OH})_{\mathrm{y}}$ for gas-phase heterogeneous photocatalytic reduction of $\mathrm{CO}_{2}$ by isomorphous substitution of $\operatorname{In}^{3+}$ with $\mathrm{Bi}^{3+}$. Adv. Sci. 5, 1700732-1700742 (2018).

31. Ghoussoub, M., Xia, M. K., Duchesne, P. N., Segal, D. \& Ozin, G. A. Principles of photothermal gas-phase heterogeneous $\mathrm{CO}_{2}$ catalysis. Energ. Environ. Sci. 12, 1122-1142 (2019)

32. Kanhere, P. D., Zheng, J. W. \& Chen, Z. Site specific optical and photocatalytic properties of Bi-doped $\mathrm{NaTaO}_{3}$. J. Phys. Chem. C. 115, 11846-11853 (2011).

33. Mizoguchi, $\mathrm{H}$. et al. New mixed-valence oxides of bismuth: $\mathrm{Bi}_{1-\mathrm{x}} \mathrm{Y}_{\mathrm{x}} \mathrm{O}_{1.5+\delta}(\mathrm{x}=$ 0.4). J. Mater. Chem. 7, 943-946 (1997).

34. Liang, C. H., Meng, G. W., Lei, Y., Phillipp, F. \& Zhang, L. D. Catalytic growth of semiconducting $\operatorname{In}_{2} \mathrm{O}_{3}$ nanofibers. Adv. Mater. 13, 1330-1333 (2001). 
35. Saison, T. et al. $\mathrm{Bi}_{2} \mathrm{O}_{3}, \mathrm{BiVO}_{4}$, and $\mathrm{Bi}_{2} \mathrm{WO}_{6}$ : impact of surface properties on photocatalytic activity under visible light. J. Phys. Chem. C. 115, 5657-5666 (2011).

36. Lei, F. C. et al. Oxygen vacancies confined in ultrathin indium oxide porous sheets for promoted visible-light water splitting. J. Am. Chem. Soc. 136, 6826-6829 (2014).

37. Hoch, L. B. et al. Carrier dynamics and the role of surface defects: Designing a photocatalyst for gas-phase $\mathrm{CO}_{2}$ reduction. Proc. Natl Acad. Sci. USA 113, E8011-E8020 (2016).

38. Hao, X. Q. et al. Zn-vacancy mediated electron-hole separation in $\mathrm{ZnS} / \mathrm{g}-\mathrm{C}_{3} \mathrm{~N}_{4}$ heterojunction for efficient visible-light photocatalytic hydrogen production. Appl. Catal. B 229, 41-51 (2018).

39. $\mathrm{Lu}, \mathrm{Y}$. H. et al. A facile green antisolvent approach to $\mathrm{Cu}^{2+}$-doped $\mathrm{ZnO}$ nanocrystals with visible-light-responsive Photoactivities. Nanoscale 6, 8796-8803 (2014).

40. Dong, F. et al. An advanced semimetal-organic Bi spheres/g- $\mathrm{C}_{3} \mathrm{~N}_{4}$ nanohybrid with SPR enhanced visible-light photocatalytic performance for NO purification. Environ. Sci. Technol. 49, 12432-12440 (2015).

41. Wang, $\mathrm{Y}$. et al. $\mathrm{CO}_{2}$ photoreduction with $\mathrm{H}_{2} \mathrm{O}$ vapor on highly dispersed $\mathrm{CeO}_{2} / \mathrm{TiO}_{2}$ catalysts: Surface species and their reactivity. J. Catal. 337, 293-302 (2016).

42. Jia, J. et al. Heterogeneous catalytic hydrogenation of $\mathrm{CO}_{2}$ by metal oxides: defect engineering-perfecting Imperfection. Chem. Soc. Rev. 46, 4631-4644 (2017).

43. Pokrovski, K., Jung, K. T. \& Bell, A. T. Investigation of $\mathrm{CO}$ and $\mathrm{CO}_{2}$ adsorption on tetragonal and monoclinic zirconia. Langmuir 17, 4297-4303 (2001).

44. Li, S. W. et al. Tuning the selectivity of catalytic carbon dioxide hydrogenation over iridium/cerium oxide catalysts with a strong metal-support interaction. Angew. Chem. Int. Ed. 56, 10761-10765 (2017).

45. Luo, C. et al. Photocatalytic $\mathrm{CO}_{2}$ reduction over $\mathrm{SrTiO}_{3}$ : Correlation between surface structure and activity. Appl. Surf. Sci. 447, 627-635 (2018).

46. Walsh, A. \& Catlow, C. R. A. Structure, stability and work functions of the low index surfaces of pure indium oxide and Sn-doped indium oxide (ITO) from density functional theory. J. Mater. Chem. 20, 10438-10444 (2010).

47. Kattel, S., Yan, B., Yang, Y., Chen, J. G. \& Liu, P. Optimizing binding energies of key intermediates for $\mathrm{CO}_{2}$ hydrogenation to methanol over oxidesupported copper. J. Am. Chem. Soc. 138, 12440-12450 (2016).

48. Fisher, I. A. \& Bell, A. T. In-situ infrared study of methanol synthesis from $\mathrm{H}_{2} /$ $\mathrm{CO}_{2}$ over $\mathrm{Cu} / \mathrm{SiO}_{2}$ and $\mathrm{Cu} / \mathrm{ZrO}_{2} / \mathrm{SiO}_{2}$. J. Catal. 172, 222-237 (1997).

49. Bianchi, D., Chafik, T., Khalfallah, M. \& Teichner, S. J. Intermediate species on zirconia supported methanol aerogel catalysts. IV. Adsorption of carbon dioxide. Appl. Catal. 105, 219-235 (1994).

50. Guglielminotti, E. Infrared study of syngas adsorption on zirconia. Langmuir 6, 1455-1460 (1990).

51. Rhodes, M., Pokrovski, K. \& Bell, A. The effects of zirconia morphology on methanol synthesis from $\mathrm{CO}$ and $\mathrm{H}_{2}$ over $\mathrm{Cu} / \mathrm{ZrO}_{2}$ catalysts Part II. Transient-response infrared studies. J. Catal. 233, 210-220 (2005).

\section{Acknowledgements}

T.Y. is thankful for financial support from the National Natural Science Foundation of China (21872081), Taishan Scholars Program of Shandong Province, and Youth Innovation and Technology Project of Shandong Province (2020KJC010). G.A.O. acknowl- edges the financial support of the Ontario Ministry of Research and Innovation (MRI), the Ministry of Economic Development, Employment and Infrastructure (MEDI), the Ministry of the Environment and Climate Change's (MOECC) and the Best in Science (BIS) Award. Also acknowledged is additional support from the Ontario Center of Excellence (OCE) Solutions 2030 Challenge Fund, the Low Carbon Innovation Fund (LCIF), Imperial Oil, the University of Toronto Connaught Innovation Fund (CIF), the Connaught Global Challenge (CGC) Fund, and the Natural Sciences and Engineering Research Council of Canada (NSERC). P.N.D. acknowledges personal funding providing by the NSERC PDF program.

\section{Author contributions}

T.Y. and G.A.O. conceived and designed the experiments. T.Y., N.L., and Linlin Wang prepared the materials for characterizations. T.Y. and N.T. carried out the batch and flow experiments for $\mathrm{CO}_{2}$ hydrogenation. W.R. and N.L. carried out the DFT calculation. T.Y. performed the in situ DRIFTS study and $\mathrm{CO}_{2}$-TPD test. Lu Wang performed the XPS characterization. M.X. and Linlin Wang carried out the ICP-AES study. T.Y and Lili Wan performed the MS test using ${ }^{13}$ C. P.D. performed the XAFS XANES experiments. T.Y., N.L., and G.A.O. co-wrote the manuscript. All authors discussed the results and commented on the manuscript.

\section{Competing interests}

The authors declare no competing interests.

\section{Additional information}

Supplementary information is available for this paper at https://doi.org/10.1038/s41467 020-19997-y.

Correspondence and requests for materials should be addressed to T.Y., N.L. or G.A.O

Peer review information Nature Communications thanks Zhi-rong Geng, and the other, anonymous, reviewer(s) for their contribution to the peer review of this work.

Reprints and permission information is available at http://www.nature.com/reprints

Publisher's note Springer Nature remains neutral with regard to jurisdictional claims in published maps and institutional affiliations.

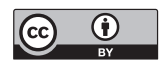

Open Access This article is licensed under a Creative Commons Attribution 4.0 International License, which permits use, sharing, adaptation, distribution and reproduction in any medium or format, as long as you give appropriate credit to the original author(s) and the source, provide a link to the Creative Commons license, and indicate if changes were made. The images or other third party material in this article are included in the article's Creative Commons license, unless indicated otherwise in a credit line to the material. If material is not included in the article's Creative Commons license and your intended use is not permitted by statutory regulation or exceeds the permitted use, you will need to obtain permission directly from the copyright holder. To view a copy of this license, visit http://creativecommons.org/ licenses/by/4.0/

(C) The Author(s) 2020 